University of San Diego

Digital USD

2005-08-01

\title{
Incidence and Clinical Predictors of Risk Factors for Inappropriate Shock in Patients with Implantable Cardioverter-Defibrillators
}

Shu-Ling Lo PhD

University of San Diego

Follow this and additional works at: https://digital.sandiego.edu/dissertations

Part of the Nursing Commons

\section{Digital USD Citation}

Lo, Shu-Ling PhD, "Incidence and Clinical Predictors of Risk Factors for Inappropriate Shock in Patients with Implantable Cardioverter-Defibrillators" (2005). Dissertations. 323.

https://digital.sandiego.edu/dissertations/323

This Dissertation: Open Access is brought to you for free and open access by the Theses and Dissertations at Digital USD. It has been accepted for inclusion in Dissertations by an authorized administrator of Digital USD. For more information, please contact digital@sandiego.edu. 


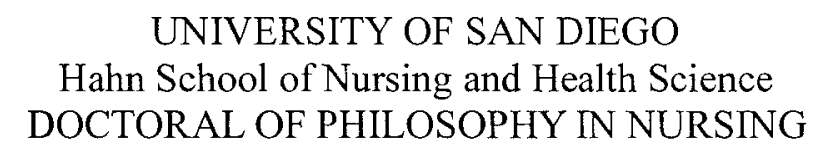

INCIDENCE AND CLINICAL PREDICTORS OF RISK FACTORS FOR INAPPROPRIATE SHOCK IN PATIENTS WITH IMPLANTABLE CARDIOVERTER-

DEFIBRILLATORS

by

Shu-Ling Lo

A dissertation presented to the

FACULTY OF THE HAHN SCHOOL OF NURSING AND HEALTH SCIENCE UNIVERSITY OF SAN DIEGO

\author{
In partial fulfillment of the \\ requirements for the degree \\ DOCTOR OF PHILOSOPHY IN NURSING
}

August 2005

Dissertation Committee:

Jane M. Georges, PhD, RN - Chairperson

Patricia A. Roth, EdD, RN

Ulrika Birgersdotter-Green, MD 


\begin{abstract}
Incidence and Clinical Predictors of Risk Factors for Inappropriate Shock in Patients with Implantable Cardioverter-Defibrillators
\end{abstract}

Shu-Ling Lo

Sudden cardiac death (SCD) is a major unresolved medical problem worldwide. Although Implantable Cardioverter-Defibrillators(ICD) are highly effective in diagnosing and treating life threatening arrhythmias, inappropriate shock therapy (IST) occurs in approximately $5-20 \%$ of ICD recipients. IST results in pain, anxiety, induction of ventricular arrhythmias, decreased battery longevity, and even death. Researchers studying clinical predictors of IST have drawn findings based on single case studies with small samples or with out-dated data. This study filled this gap by describing the incidence and co-existing clinical predictors of IST.

\title{
Methodology
}

This descriptive, retrospective study analyzed the incidence and clinical predictors of IST in ICD adult recipients by utilizing a five-year retrospective review ICD interrogation records and medical charts at a university hospital.

\section{Results}

During a mean follow-up period of $24.1 \pm 16.2$ months, 20 out of 119 ICD recipients received appropriate shock, and IST occurred in 13(9\%) out of 119 ICD recipients. A total of 16 IST experiences occurred among these 13 patients. Eight subjects received IST for atrial fibrillation (AF)/atria tachycardia or sinus tachycardia/normal sinus rhythm, two for double counting, two for lead problems, and one for drug interaction. Of these, 12 out of 98 men received IST. One out of 21 women received IST. Using Chi-square and logistic regression analysis, results showed only $\mathrm{AF}$ as a significant predictor $(\mathrm{p}=.002 \mathrm{vs}$ 0.001 ) and remains the main cause of IST. Although the variables of age, gender, NYHA class LVEF and structural heart disease showed no significant relationship. Trigger events occurred during clinical interventions and were noted in this study.

\section{Conclusion}

The clinical characteristics of patients prone to IST should be carefully considered when planning clinical interventions. With the rapid expansion of this patient population, a multisite expanded longitudinal study is indicated to confirm the results seen in this initial descriptive study. 
Page

LIST OF TABLES $\quad$ iv

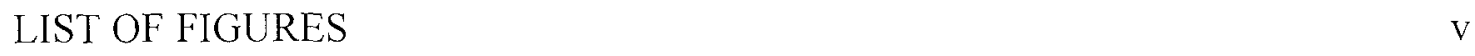

LIST OF APPENDICES Vi

CHAPTER I : STUDY PROBLEM AND ITS SIGNIFICANCE I

Background 1

Statement of Problem 3

Impacts of Inappropriate Shock 3

Physiological Impact $\quad 3$

Psychosocial Impact $\quad 4$

Economical Impact $\quad 5$

Predisposing Clinical Characteristics Factors Are Not Well Known 5

$\begin{array}{ll}\text { Current Status of Intervention Programs } & 6\end{array}$

$\begin{array}{ll}\text { Future Technological Considerations } & 7\end{array}$

The Role of Cardiovascular Nurse in the Management of Inappropriate

Shock Therapy from a Physiological Aspect $\quad 8$

$\begin{array}{ll}\text { Purpose of Study } & 9\end{array}$

Specific Aims

CHAPTER II : REVIEW OF LITERATURE 11

The Relevant Arrhythmia of Implantable Cardioverter Defibrillator 11

$\begin{array}{ll}\text { Supraventricular Arrhythmias } & 11\end{array}$

$\begin{array}{ll}\text { Supraventricular Tachycardia } & 11\end{array}$

Atrial Fibrillation $\quad 12$

$\begin{array}{lr}\text { Ventricular Arrhythmias } & 12 \\ \text { Ventricur }\end{array}$

Ventricular Tachycardia $\quad 12$

Ventricular Fibrillation $\quad 13$

$\begin{array}{ll}\text { Mechanisms of Fibrillation and Defibrillation } & 14\end{array}$

$\begin{array}{ll}\text { Role of Reentry } & 14\end{array}$

The Electrophysiological Concepts of Ventricular Defibrillation 15

Development of Defibrillator 16

The Implantable Cardioverter Defibrillator 16

Historical Development of Implantable Cardioverter Defibrillator $\quad 16$

Components of Current Implantable Cardioverter Defibrillator $\quad 17$

Functions of Implantable Cardioverter Defibrillator $\quad 18$

Appropriate Shock vs Inappropriate Shock 20

$\begin{array}{ll}\text { Interrogation of The Implantable Cardioverter Defibrillator } & 21\end{array}$ 
TABLE OF CONTENTS (Continued)

Page

Review of Literature on Inappropriate Shock 22

Overall Factors Contribute to Inappropriate Shock with Atrial 22

Fibrillation Focus

Individual Factors $\quad 26$

Lead Problems $\quad 26$

Double Counting $\quad 27$

Generator Malfunction Issues $\quad 29$

Diaphragm Myopotential $\quad 29$

Electromagnetic Interference $\quad 30$

Drug Interaction $\quad 31$

Clinical Characteristics and Other Factors $\quad 33$

Death Events Related to Inappropriate Shock Therapy 35

Summary and Conclusions $\quad 36$

CHAPTER III : METHODOLOGY 46

Research Design $\quad 46$

$\begin{array}{ll}\text { Research Setting } & 47\end{array}$

Sample $\quad 48$

Data Collection $\quad 49$

Data Collection Instrument 49

Validity and Reliability of ICD Records and Chart Records 49

Data Collection Procedures $\quad 50$

Data Analysis $\quad 50$

Statistics Analysis $\quad 50$

Human Subjects $\quad 50$

Risk Management

Potential Benefits $\quad 54$

Risk Benefit Ratio

CHAPTER IV : RESULTS

Subjects and Sample Characteristics $\quad 58$

Data Analysis Related to the Aims of This Study $\quad 59$

Specific Aim \# 1

Specific Aim \# 260

Specific Aim \# $3 \quad 64$

Specific Aim \# $4 \quad 65$

Descriptions of 13 Inappropriate Shock Therapy Patients $\quad 70$

Summary 71

ii 
TABLE OF CONTENTS (Continued)

Page

$\begin{array}{ll}\text { CHAPTER V : DISCUSSION } & 73\end{array}$

$\begin{array}{ll}\text { Overview } & 73\end{array}$

Incidence Rates $\quad 74$

Age and Gender $\quad 74$

Atrial Fibrillation $\quad 74$

$\begin{array}{ll}\text { NYHA Functional Class } & 75\end{array}$

$\begin{array}{ll}\text { Ejection Fraction } & 75\end{array}$

$\begin{array}{ll}\text { Structural Heart Disease } & 75\end{array}$

$\begin{array}{ll}\text { Lead Problems } & 76\end{array}$

$\begin{array}{ll}\text { Drug Interaction } & 76\end{array}$

Electrolyte Imbalance $\quad 76$

Events Occurring at the time of Inappropriate Shock Therapy 77

$\begin{array}{ll}\text { Clinical Implications } & 78\end{array}$

$\begin{array}{ll}\text { Limitations } & 78\end{array}$

$\begin{array}{lr}\text { Suggestion for Future Research } & 80\end{array}$

$\begin{array}{ll}\text { REFERENCES } & 82\end{array}$

$\begin{array}{ll}\text { APPENDICES } & 96\end{array}$

$\begin{array}{ll}\text { APPENDIX A : } & \text { Table 1. Summary of ICD Trails for the Secondary } \\ & \text { Prevention of SCD }\end{array}$

Table 2. Summary of ICD Trails for the Primary

APPENDIX B : 2002 Indications for Implantable Cardioverter Defibrillator Therapy (ACC/AHA/NASPE) Practice

APPENDIX C : Nursing Research related to Care of ICD Recipients 103

APPENDIX D : ICD INAPPROPRIATE SHOCK THERAPY STUDY DATA SHEET $\quad 107$

APPENDIX E : Approval Letter From the Committee of Human Research 108 - University of San Diego

APPENDIX F : Approval Letter From the Committee of Human Research - University of California San Diego Medical Center 109 


\section{LIST OF TABLES}

Page

Table 1 Ventricular Tachycardia Defined by Category

Table 2 Inappropriate Shock Therapy Events in ICD Studies with Varying Criteria

Table 3 Demographic and Clinical Characteristics of Subjects 58

Table 4 Shock Profiles $\quad 60$

Table 5 Inappropriate Shock Profile for IST Patients $\quad 60$

Table 6 Inappropriate Shock in Chi-Square Comparisons between IST and 62 Non-IST patients

Table 7 Likelihood Ratio Tests 63

Table 8 Incidence of ISTs by Variable Factors

Table 9 Characteristics of Subjects and Incidence of Inappropriate Shock Therapy 


\section{LIST OF FIGURES}

Page

$\begin{array}{lll}\text { Figure } 1 \text { Appropriate shock } & 20\end{array}$

Figure 2 Scheme Summary of Subjects Enrolled in the Study 38

$\begin{array}{lll}\text { Figure } 3 \text { Inappropriate shock - 1 } & 72\end{array}$

$\begin{array}{lll}\text { Figure } 4 & \text { Inappropriate shock - } 2 & 72\end{array}$ 


\section{CHAPTER I \\ STUDY PROBLEM AND ITS SIGNIFICANCE}

Background

Sudden cardiac death (SCD) is defined as death from abrupt, unexpected circulatory arrest occurring within a short period, generally less than an hour, following the onset of acute symptoms (Jeanne, Poole \& Bardy, 2004). SCD occurs in about 450,000 people in the United States each year (American Heart Association, 2005). It also affects a significant number of people in many other countries (Connolly, Gent, Roberts, 2000; Spector, 2005). SCD is a major unresolved public health problem in the U.S. and throughout the world. It is often attributed to untreated, life threatening, ventricular arrhythmia (Bardy, 2004). Attempts to prevent SCD with antiarrhythmic agents have met with little success and may even increase mortality (Cardiac Arrhythmia Suppression Trial II Investigators, 1992). Some nontypical antiarrhythmic agents (e.g., ß blockers), have demonstrated a reduction in arrhythmic deaths by reducing the ischemic burden. Revascularization is most often used as the first line of intervention for the reduction of sudden death risk in ischemic patients (Spector, 2005). However, the limited efficacy of SCD prevention and the failure of resuscitation from out-of-hospital cardiac arrest renders SCD a significant problem. The development of the implantable cardioverter defibrillator (ICD), which almost instantly detects and treats life - threatening ventricular arrhythmia has in recent years revolutionized the treatment of SCD (Mirowki, Reid, Mower, Watkins, \& Gott, 1980). 
IST in patients with ICDs 2

The advent of the ICDs has resulted in a significant decrease in the rate of SCD from ventricular tachycardia (VT) and ventricular fibrillation (VF) in specific populations (Moss, Hall, Cannom, Daubert, Higgins, Kiel, et al., 1996). With the advent of monitoring capabilities from the ICD, there has been a tremendous change in the prevention of sudden arrhythmia death (Moss, Zareba, \& Hall, 2002; Naccareli, 2004). The ICD is responsible for sending electrical signals that satisfy programmed criteria and is highly effective in reverting such rhythms back to normal (Klein, Auricchio, Reck, \& Geller, 1999). An appropriate shock was defined as a spontaneous ICD discharge that terminated with such clinical symptoms as palpitations, nausea, dizziness, lightheadedness, or syncope (Schreieck, Zrenne, Kolb, Ndrepepa, \& Schmitt, 2001). The ICD functions by delivering shocks in response to electrical signals that satisfy preprogrammed criteria, and it is highly effective in reverting VT and VF to normal rhythms (Klein, Auricchio, Reck, \& Geller, 1999). Clinical trials have demonstrated that the ICD is superior to medication in prolonging the lives of individuals with a history of prior or inducible, sustained, ventricular arrhythmia (i.e., VT longer than 30 seconds; Antiarrhythmics Versus Implantable Defibrillators [AVID], 1997; Kuck, Cappato, Siebels, \& Ruppel, 2000). With the completion of multiple randomized clinical trails, ICDs have emerged as the dominant therapy for the secondary and primary prevention of SCD (Bardy et al., 2005, Connolly et al., 2000; Kuck et al.; Moss et al., 2002; Sheldon, Connolly, Krahn, 2000). In addition to the secondary and primary prevention of SCD, ICDs have an emerging indication for dilated cardiomyopathy (DCM) (Bänsch, Antz, Boczor, Volkmer, Tebbenjohanns, Karlheinz et al., 2002). The current "Practice Guidelines of Indications for Implantable Cardioverter - Defibrillator Therapy" 
IST in patients with ICDs 3

(Gregoratos, Abrams, Epstein, Freedam, David, \& Hayes et al., 2002) is based on the clinical trails (Appendix A) developed by the expert panel of ACC/AHA/NASPE in 2002 (Appendix B). Along with the therapies for the secondary and primary prevention of SCD, the ICD indications expanded to chronic heart failure and DCM (Abraham, 2003; Guidant Atrial Features Guide, 2001). A substantial increase in the implantation of ICDs is expected because of these expanded indications.

\section{Statement of the Problem}

ICDs are accurate and effective in the diagnosis and treatment of VT and VF. However, inappropriate shock therapy (IST), defined as shocks occurring in the absence of life threatening ventricular arrhythmias, occurs in approximately $5 \%-20 \%$ of ICD patients (Grimm, Flores, \& Marchlinski, 1993; Lauria, Glikson, Brady, Lexvold, Rasmussen, Hodge, et al., 2001, Rosenqvist, Beyer, Block, Den Dulk, Minten, \& Lindemans, 1998; Theuns, Klootwijk, Simoons, \& Jordaens, 2005). Inappropriate therapy shocks are hazardous because the consequences of IST are severe and have been reported in many studies (Messali, Thomas, Chauvin, Conmel and Leenhardt, 2004; Steinbrook, 2005).

\section{Impacts of Inappropriate Shock}

\section{Physiological Impact}

Patients have described the sensation of an inappropriate shock as a pain similar to being punched in the chest or kicked by a horse (Thomas, 2001). IST, apart from being painful, may also cause myocardial damage, as documented in animal and human studies (Epstein, Kay, Plumb, Dailey, Peter, \& Anderson, 1998). Due to IST, 
IST in patients with ICDs 4

proarrhythmia is also a frequently reported event (Pinski \& Fahy, 1995). Pinski and Fahy reported on death from IST, and Messali, Thomas, Chauvin, Coumel, and Leenhardt (2004) also recorded deaths in their research, with the rate varying from $0.4 \%$ to $8 \%$. The risk for proarrhythmia appeared to be most common in situations with fast superventricular rhythms with a concomitant increase in sympathetic discharge, raterelated disease in ventricular refractoriness, or myocardial ischemia (Pinski \& Fahy, 1995).

\section{Psychological Impact}

Although the ICD is a lifesaving device, living with the possibility of receiving a defibrillating shock at any time can be emotionally devastating. One small study (Dougherty, 1995) and a national survey (Sears \& Conti, 2002) found that patients receiving ICD shocks, along with their families, experienced more anxiety, anger, depression, and stress than patients and families who had not received shocks. A study of 57 patients (Luderitz, Jung, Diester, Marneros, \& Manz, 1993) found that patients who had experienced five or more shocks from an ICD had a higher state of anxiety than those who experienced fewer than five shocks. In another study of the impact of ICD therapy (Godemann, Butter, Lampe, Linden, Schlegl, Schulth, et al., 2004), the results demonstrated that, in patients who have two or more ICD discharges annually, the incidence of panic disorders and agoraphobia were higher than in those who only received a single ICD discharge annually. Patients' level of psychological symptoms was correlated with fear of ICD malfunction, particularly anxiety, depression, and fear of death (Dougherty, 2004). The manner of how one's quality of life was affected by ICD 
IST in patients with ICDs 5

shock(s) has been reported in several studies (Sears, Eads, Marhefka, 2002; Carroll \& Hamilton, 2005).

Economic Impact

Other major negative impacts of IST include the induction of ventricular arrhythmias and a decrease in life longevity of battery caused by frequent shocks (Lin, Dixit, Russia, \& Hsia, 2004). As the results of these effects, the replacement of already expensive ICDs will require additional costs. In addition, the fees of diagnostic procedures, treatments, and frequent clinical visits' fees must be paid as well. The unfavorable cost effectiveness resulting from ISTs ultimately may become a financial burden for the health care system.

Predisposing Clinical Characteristically Factors Are Not Well Known Many inappropriate ICD discharges are caused by supraventricular arrhythmias that are triggered by a problem with the ICD device, or that occur at a time when the environment interferes with the ICD (Pinski \& Trohman, 2002; Rinaddi, Simmon, Bostock, Elliot, \& Gill, 2004). However, patients and clinicians report that inappropriate shocks still occur with no identifiable causes (Champagne, Geelen, Philippon, \& Brugada, 2005; Glikson, 2004). The literature review demonstrated that, in the majority of patients who are at risk for an IST, the clinical predictors of ISTs are not well known. In addition, neither the timing nor the circumstances under which an IST occurred (e.g., exercise, dehydration) were correlated to occurrence of inappropriate therapy (Healy, Ngarmukos, \& Rosenthal, 2002). Many case studies, consisting of only one to four patients, provided in-depth information about the incidence of inappropriate shock (Healy, 2002; Messali, 2004; Peters, 1998). However, these findings cannot be generalized due to limited data 
IST in patients with ICDs 6

(Burns \& Grove, 2004). As a result, there exists no exhaustive list of what may or may not affect an ICD. The multitude of variables makes it impossible to know how a device will respond to various sources of interference. Misinformation and outdated information perpetuated within the medical community cloud these issues.

\section{Current Status of Intervention Programs}

Many respected nursing researchers have explored the impact of ICD therapy, including interventions to promote the quality of life for ICD recipients and their families (Carlesson, Olesson \& Hertervig, 2002; Shea, 2004; Sneed, 1997; Vitale \& Funk, 1995). Educational intervention programming related to psychological aspects has also been discussed extensively (Dougherty et al., 2004; Higgins, 1990; Sneed, Fench, \& Michel, 1997; White, 2002). However, care practices are likely to have evolved that do not encompass the physiological elements. Few studies have provided information regarding the experience of shock itself or have made distinctions between appropriate shock and inappropriate shock. Recently, an educational program developed by Dougherty et al. made suggestions for the educational intervention of ICD recipients. Their suggestions were based solely on the number of shock events and the level of pain experienced, which might not accurately reflect the seriousness of a shock event. For example, a patient could feel pain when he/she experienced a "phantom shock" in which no true shock occurred but the patient claimed to feel pain). Conversely, a patient might not feel pain due to his/her loss of conscious from a high-energy shock. In a recent nursing care journal discussing the issues of patients with ICDs, Dunbar (2005) intended to discuss all areas of concerns from psychosocial aspect. However, it was not clear whether the author intended to give information to prevent an inappropriate shock or address 
appropriate shock in the nursing care of patients with ICDs. The author stated that, "Known predictors of inappropriate shock are history of atrial tachyarrhythmia and recurrent ventricular tachycardia that have triggered appropriate therapy"(p.297). Moreover, there are still many other risk factors that could trigger inappropriate shocks and appropriate shocks. Hence, without sufficient published information, it would be difficult to provide effective educational programs. O'Brien, Langberg, Valderrma, Kirkendoll, Romeiko and Dunbar (2005) investigated patients and families involving ICD storms, where patients experience two or more appropriate and/or inappropriate shocks within 24 hours. This study provided great insight into the effects of an ICD storm and the management of shocks; however, intervention for preventing the occurrence of an inappropriate shock event remains an unsolved problem. Appendix C summarizes the last five years of nursing research related to care of the ICD recipients.

\section{Future Technological Considerations}

As ICDs become more complicated, the incidence of inappropriate shock is likely to increase (Rinaddi, Simmon, Bostock, Elliot, Bcknall, \& Gill, 2004). In addition, there has been a corresponding increase in the number and complexity of patients seen in follow-up visits after ICD implantation. This increased visitation volume demands that clinical practice create alternative methods to safely and effectively monitor these patients. Recently, the internet-based remote monitoring service has allowed clinicians to remotely manage their patients' ICDs and chronic diseases. The network is comprised of a patient monitor, a secured server, and clinician and patient websites. Under clinical direction, patients interrogate their ICDs at home and transmit data to a secure server via standard telephone lines (Joseph, Wilkoff, Dresing, Burkhardt, \& Khaykin, 2004). 
Patients have become critical consumers of health care and are frequently using the internet as a resource for their health concerns and treatment options. Cardiovascular nurses have a unique opportunity to assist patients using this modality. Web pages provide interactive patient education, including behavioral interventions, for risk reduction management in ICD therapy. This study serves as an exemplar for how cardiovascular nurses can work with these valuable tools for patient care.

The Role of Cardiovascular Nurses in the Management of Inappropriate Shock Therapy from a Physiological Aspect

The nursing profession plays an important role in the delivery of health services, particularly for cardiovascular patients. Nurses are responsible for recognizing "cue complexes," or syndromes, and for providing prompt emergency treatment (e.g., cardiac resuscitation). Nurses also provide appropriate information to the ICD recipients and their families regarding the diagnosis or plan of therapy following physician-nurse appraisal (Roger, 1971). One goal of advanced cardiovascular nurses is to integrate technology with patents' everyday lives. Cardiovascular nurses can play a pivotal role in providing optimal care for ICD patients. Through effective nursing interventions utilizing current guidelines and updating information in a multidisciplinary forum, nurses can develop realistic, scientifically-based guidelines for ICD patients. To date, no study has systemically analyzed clinical conditions as risk factors predisposing patients to an inappropriate shock, and the phenomenon remains relatively unexplored. As nurse scientists, advanced cardiovascular nurses are taking leadership roles in major interdisciplinary organizations and need knowledge and skills to contribute in a 
competitive, ever-evolving field. Therefore, it is imperative to investigate the clinical characteristics of ICD patients that may be predictive of inappropriate shock in a broad population.

\section{Purpose of the Study}

The overall purpose of this study was to describe the incidence of appropriate and inappropriate shock occurrence and to investigate the clinical predisposing factors for an inappropriate shock in a group of ICD recipients treated at a university medical center in Southern California during the period from July 2000 to May, 2005. The specific aims were as follows:

Specific Aim \# 1

To describe the incidence of appropriate and inappropriate shock occurrence in a group of ICD recipients who visited the university medical facility between July, 2000 and May, 2005 for emergent and routine follow-up visits.

Specific Aim \# 2

To describe the relative risk relationships between age group and IST, gender and IST, heart disease severity and IST, structural/ non-structural heart disease and IST, and the history of atrial fibrillation and IST.

Specific Aim \# 3

To describe the frequency of ISTs in a group of ICD recipients by risk factors (e.g., atrial fibrillation, lead problems, double counting) and the frequency and proportion of each risk factor associated with an IST. 
Specific Aim \#4

To investigate significant correlations between clinical factors and an IST, and, when taken in combination, to reveal any clinical predictability for the incidence of an IST. Clinical factors analyzed include demographic characteristics, history of previous underlying heart disease, ejection fraction, and medications taken at the time of the IST. 


\section{CHAPTER II}

\section{REVIEW OF LITERATURE}

Inappropriate shocks from ICD therapy occur in a combination of events involving the interference of the patient, device and environment. Regarding the causes of IST, it is imperative to understand the foundation it is built upon. For this reason, the author has scrutinized the pathways that lead to IST.

This section begins with a review relevant arrhythmias of implantable Cardioverter-defibrillator. The concepts of reentry and defibrillation are discussed, because they play important roles in the events of IST. The author then proceeds to discuss the development of ICD, its multiprogrammable features and the function of this modern device. This section concludes with the significance of interrogation concerning ICD in follow-up visits.

The Relevant Arrhythmias of Implantable Cardioverter -Defibrillator Therapy:

\section{Supraventricular Arrhythmias}

\section{Supraventricular Tachycardia.}

Supraventricular tachycardia (SVT) is a rapid, regular heart rate, where the heartbeat ranges from 150 to 250 beats per minute in the atria. The condition can be caused by a number of factors, or it can occur spontaneously. As a result, the heart beats abnormally fast and the oxygen supply to the brain is reduced. Some people experience no symptoms, yet others may experience dizziness, syncope, shortness of breath, pale color, chest tightness, and chest pain (Ganz, 2002). 
IST in patients with ICDs 12

\section{Atrial Fibrillation}

Electrical signals in the atria are fired in a very fast and uncontrollable manner. Atrial signals create a pattern of rapid and chaotic beating that starts at 350 beats per minute and ranges higher. Instead of a single electrical signal followed by coordinated atrial contraction, there is quivering of the atrial muscle. Not all signals are conducted through the AV node. Ventricular rates may vary from 100 to 180 . Atrial fibrillation (AF) may occur in a sustained manner or may occur episodically (Woods, Froelicher, Motzer, \& Bridges, 2005).

Ventricular Arrhythmias

The two major types of the ventricular arrhythmias are ventricular tachycardia (VT) and ventricular fibrillation (VF). VT is a regular heartbeat arising in the ventricles. Ventricular fibrillation occurs when the ventricles go out of control, quivering and beating ineffectively, thereby stopping the pumping action. If a more normal rhythm is not restored promptly - within three to five minutes - the patient will suffer brain and heart damage and will die (Kastor, 2000; Woods, Froelicher, Motzer, \& Bridges, 2005).

\section{Ventricular Tachycardia.}

Ventricular tachycardia occurs when the ventricles produce impulses that make the heart beat too quickly. With this disorder, the heart tries to beat 150 a minute or more. The heart does not fill with enough blood between beats to meet the body's needs. Symptoms include a pounding sensation, dizziness, and sometimes fainting occurs (Kastor, 2000). There are several categories that VT falls under. Please see Table 1. 
Table 1

Ventricular Tachycardia Defined by Category

\begin{tabular}{|l|l|}
\hline \multicolumn{1}{|c|}{$\begin{array}{l}\text { Dategory 1 } \\
\text { Duration / Duration of Tachycardia }\end{array}$} \\
\hline $\begin{array}{l}\text { Transient also called } \\
\text { unsustained or nonsustained } \\
\text { (NSVT) }\end{array}$ & $\begin{array}{l}\text { Beats are no longer than 30 seconds, with a minimum of 3 } \\
\text { consecutive ventricular beat and without cardiovascular } \\
\text { deterioration. }\end{array}$ \\
\hline $\begin{array}{l}\text { Sustained in which the } \\
\text { paroxysms last (SMVT) }\end{array}$ & $\begin{array}{l}\text { More than 30 seconds, with cardiovascular deterioration, } \\
\text { requires immediate treatment to prevent cardiovascular } \\
\text { collapse. }\end{array}$ \\
\hline Incessant & $\begin{array}{l}\text { Most of the time. } \\
\text { Electrocardiographic Appearance / QRS Form }\end{array}$ \\
\hline $\begin{array}{l}\text { Monomorphic ventricular } \\
\text { tachycardia }\end{array}$ & $\begin{array}{l}\text { Each of the QRS complexes has identical or nearly } \\
\text { identical. }\end{array}$ \\
\hline $\begin{array}{l}\text { Polymorphic ventricular } \\
\text { tachycardia (also called } \\
\text { Torsade de Point, TdP) }\end{array}$ & $\begin{array}{l}\text { The morphology (form) of the QRS complexes change } \\
\text { A particularly rapid, dangerous form of VT that often } \\
\text { occurs as a result of certain medications or in patients with } \\
\text { congenital Long QT syndrome. }\end{array}$ \\
\hline \multicolumn{1}{|c|}{ The Presence or Absence of Heart Disease/ Examples } \\
\hline $\begin{array}{l}\text { Without structural heart } \\
\text { disease or idiopathic. }\end{array}$ & $\begin{array}{l}\text { Long QT syndrome, Brugada syndrome, short QT } \\
\text { syndrome. }\end{array}$ \\
\hline
\end{tabular}

Source: Modified from Kastor, J. A. (2000). Arrhythmias. $\left(2^{\text {nd }}\right)$. Philadelphia : W. B.

Sunders, p.343.

\section{Ventricular Fibrillation}

Ventricular fibrillation (VF) is a chaotic heart rate resulting from multiple areas of the ventricles attempting to control the heart's rhythm. VF sometimes can occur spontaneously, but generally it is caused by heart disease, or when VT has persisted too long. When the ventricles fibrillate, they cannot contract normally, hence, they cannot effectively pump blood. The instant VF begins, effective blood pumping stops. VF quickly becomes more erratic, resulting in sudden cardiac arrest or sudden cardiac death. This arrhythmia must be corrected immediately via shock from an external defibrillator 
or an ICD. The defibrillator can stop the chaotic electrical activity and restore normal rhythm (Ganz, 2002; Kastor, 2000).

\section{Mechanisms of Fibrillation and Defibrillation \\ The Role of Reentry}

The available clinical and experimental evidence suggests that instability in VT leading to the degeneration of the VT into VF is a phenomenon of re-entry, which is a disorder of impulse conduction (Singer, 1994). The restitution hypothesis suggests a mechanism for the development of instability in re-entry that may explain the predisposition for degeneration to fibrillation (Adgey, Spence, \& Walsh, 2005; Spector, 2005).

Re-entry is a continuous electrical activity in which each wave re-circulates to produce the next wave. For activation waves to propagate continuously, two paths for conduction separated by unexcitable tissue are required. Activation must spread around one side of the unexcitable tissue allowing the other side time to recover from inactivation in order to re-excite the tissue when the wave front returns. Tissue refractory periods limit re-entry: the conduction time around the circuit must be greater than the refractory period of each component of the circuit. Therefore, decreased conduction velocity or a decreased refractory period facilitates re-entry by decreasing the likelihood that the activation wave front will encounter its own refractory tail, ending the tachycardia (Woods, Froelicher, Motzer, and Bridges, 2005)

In clinical practice, re-entrant circuits can occur in two circumstances. First, a fixed re-entry is the site of an anatomic conduction block that resulted from scar tissue 
and frequently occurs in the setting of ischemic cardiomyopathy (Adgey, Spence et al., 2005).

The second circumstance during which functional re-entry may occur is in the absence of anatomic obstacles. In this instance, the circuit path is determined by tissue refractoriness. Factors leading to the correct conditions that favor such re-entry mechanisms include increased heart size through hypertrophy or dilatation, drugs that alter the length of the refractory period, and areas of cardiac disease. A group of transiently unexcitable cells (i.e., secondary to refractoriness) creates an obstacle to the conduction around which a circuit can form (Adgey, Spence et al., 2005).

\section{The Electrophysiological Concepts of Ventricular Defibrillation}

The mechanism of ventricular defibrillation has been extensively investigated over many decades. However, the definite mechanism of defibrillation is still unclear and many hypotheses have been proposed. The most influential was the critical mass hypothesis. First proposed by Garrey in 1914 (Spence, 2003), it was supported by several other electrocardiologists. Garrey found that a fibrillating heart would no longer fibrillate when the myocardial mass decreased into small pieces (Adgey, Spence et al., 2005). The studies from Schunder, Stoekle, Gold, West, \& Denniston (1973) and Miroski, Mower, Gott, Brawley, \& Denniston (1973) showed that successful defibrillation could occur when low energy shocks were delivered though a transvenous catheter. This result suggested that the shock might need to defibrillate only the critical mass of the ventricles to get a successful outcome. In 1975, Zipes, and his colleagues provided further validation for this idea by demonstrating that the chemical depolarization of a critical mass of ventricular myocardium $(\sim 75 \%)$, using selective infusion of potassium chloride 
IST in patients with ICDs 16

into the left coronary artery, would successfully abolish ventricular fibrillation. Therefore, if a sufficient voltage potential gradient could be generated by a shock to halt the fibrillation activation fronts in the myocardium, defibrillation could occur (Adgey, Spence et al., 2005).

\section{Historical Development of the of Defibrillator}

Development of practical defibrillators began in the 1920 s with response to an increasing number of electrical shock accidents and deaths. In 1947, Beck et al. performed the first successful human defibrillation using specially designed internal cardiac paddles to resuscitate a 14-year-old boy who had become pulse-less during elective chest surgery. In 1956, Zoll et al. performed the first successful human external defibrillation using a 15 -amp AC current that produced 710 volts applied across the chest for 0.15 seconds. In 1961, Alexander, Kleiger, and Lown first described the use of AC current for terminating VT. Work by Lown et al. in the early 1960's demonstrated the superiority and safety of DC over AC for defibrillation. Ambulance-transported Belfast physicians first performed successful pre-hospital defibrillation in 1966. Defibrillation by emergency medical technicians (EMTs) without the presence of physicians was first performed in Portland, Oregon, in 1969 and was reported in 1972. (Bocka, 2005)

The Implantable Cardioverter Defibrillator

In the 1960s, Mirowski (1985) conceived of the idea of an automatic implantable defibrillator. The first ICD was implanted in a young woman as a prophylaxis against SCD in 1980. The U.S. Food and Drug Administration approved the device in 1985. 
The earliest devices weighed up to 300 grams, had a battery life of three years, and were implanted in the subcutaneous layer of the abdomen with epical screw-in leads, and were sutured to the pericardium (Wolfe, Kosinski, \& Grubb, 1998). A second generation of devices, developed in the mid-1980s, did not require thoracotomy, but used a transvenous defibrillating lead. These second generation ICDs employed cardioversion, were programmable, detected ventricular arrhythmias better, and delayed electrical therapy. In the 1990's, the third generation ICDs had multiple features, tiered therapies, enhanced programmability, and increased sophistication, as well as being designed to target energy delivery. Additionally, these advanced devices weighed less than 40 milligrams and had a battery life of eight years (Fetzer, 2003).

Components of Current ICDs

The current ICD consists of a pulse generator and one or more leads. An epoxy resin header at the top of the generator connects pacing and defibrillation electrodes (DiMarco, 2003; Zipes, Libby, Bonow, \& Braunwald, 2005).

The newer models provide a daily rhythm history with as many as 150 certain therapy events stored in their memory. The devices that store a graphic image of a patient's arrhythmia, called an electrogram (EGM), are ready for interrogation by an external analyzer. However, if events go beyond the capacity of storage, the oldest rhythm would be discarded and the newest would be stored instead (DiMarco, 2003).

An ICD battery usually functions between four and eight years, depending on the number of shocks and/or the pacing it sends. When the battery runs down, a new ICD must be implanted (DiMarco, 2003; Fetzer, 2003; Zipes, Libby, Bonow, \& Braunwald, 2005). 
IST in patients with ICDs 18

The leads are responsible for capturing the electrical activity that goes toward internal sensing, provide a site for pacing and defibrillating. Recent technological improvements in electrode design have led to improved features. The transvenous leads have decreased the amount of energy required to defibrillate. This decrease in energy has rendered the need for the larger epicardial patches and electrodes rendering sternotomy incisions obsolete. Therefore, these transvenous leads are now accepted as a standard (Seidl \& Senges, 2003). Currently, the following models are available: (a) a single chambered, ventricular-only device that is usually placed in the right ventricle; (b) a dualchambered atrial and ventricular device with leads placed in the right ventricle and atrium; and (c) a biventricular ICD, whose leads are attached in the right atrium, the right ventricle and the left ventricle. These techniques help the heart beat in a more balanced way and are specifically used for patients with heart failure. .

\section{Functions of Implantable Cardioverter-Defibrillator}

The ICD has three major functions: monitoring, detecting and delivering. The ICD program monitors the $\mathrm{R}$ wave of the electrocardiogram and counts the number of QRS complexes per minute on a beat-to-beat basis (Fetzer, 2003). The ICD determines when the ventricular rate exceeds the programmed limit. Many ICDs have a VT zone (e.g., 150-200 beats per minute $[\mathrm{bpm}]$ ) and a VF zone (e.g., $>200 \mathrm{bpm}$ ). When the ICD has detected the ventricular rate and QRS morphology abnormalities that exceed its programmed limits, the program triggers the antitachycardia pacing therapy (ATP). When the heart beats too fast, a series of small electrical impulses are delivered to the heart muscle to restore a normal heart rate and rhythm for VT, or delivers a shock to terminate VF (Clemo \& Ellenborg, 2001; DiMarco, 2003). 
When the shock program has been initiated, the device can be programmed to deliver a first shock from a minimum of 1 joule to a maximum of 41 joules, depending on the energy level required; traditionally starting at 10 joules. The charging time can take 0.1 to 7 seconds. After delivering the first shock, a 5 to 25 second delay is programmed to allow the ICD to detect any continuing dysrhythmia and recharge. Second, third, fourth, and fifth shocks are delivered at the maximum energy level if needed. Newer ICD models can be programmed for six shocks, and some will deliver a maximum of eight shocks. 
Appropriate Shock vs Inappropriate Shock

Appropriate shock is defined as an ICD delivered discharge (shock) at the presence of VT or VF

Inppropriate shock is defined as an ICD delivered shock at the absence of VT or VF, usually with no preceding symptoms.

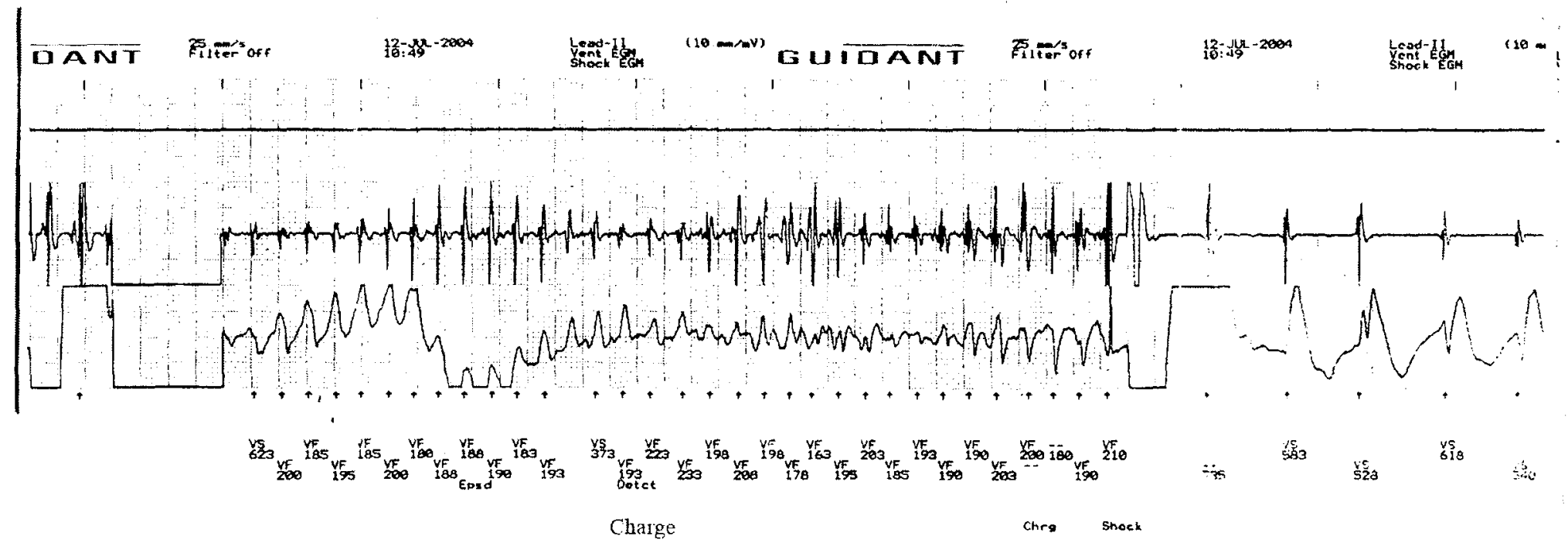

Figures 1

Appropriate shock 
IST in patients with ICDs 21

Interrogation of the ICD

The interrogation procedure is typically done every three months in a specialized pacemaker/ICD follow-up clinic. A cardiac electrophysiologist, assisted by a trained technician or senior cardiovascular nurse, performs the procedure. Interrogation is also performed as the device approaches elective replacement or in response to symptomatic events (e.g., shocks).

During ICD interrogation, a "wand" is passed over the device and is attached to a programmer for communicating by means of electromagnetic coupling. Thus, the electrophysiologist is able to determine what electrical therapies have been experienced. The interrogation process checks lead integrity and battery status. Based on the revealed information, the device can be adjusted to optimize detection and therapy parameters. Most ICDs record the patients' electrocardiographic tracing at the time of arrhythmia detection. This information can be analyzed at follow-up visits to determine the nature of the arrhythmia and the efficacy of the electrical therapy that was given (Groh \& Foremn, 1998).

An implantable defibrillator, prescribed for people whose hearts beat dangerously fast, operates differently from a pacemaker. When a defibrillator detects a fast heart rate, it delivers electrical therapies to restore a normal rhythm. Depending on the patient's condition, these therapies can begin mildly and become progressively stronger as needed (ATP). The highest energy therapy is called defibrillation, and it provides treatment similar to defibrillation paddles used by medical personnel (Fetzer, 2003). Over 250,000 defibrillators have been implanted worldwide since 1985 (Metronic, 2005). 


\section{Review of Literature on Inappropriate Shock}

The ICD has achieved a preeminent role in the treatment of life-threatening, ventricular arrhythmias. The most common arrhythmias-related complaint among ICD patients is the subjective feeling of shock. The variant causes of inappropriate shock therapy remains a major clinical problem and the contributing factors remain unclear. Weber, Boecker, Block(1996) reported that the causes of IST are many, including: AF, the most frequent cause of IST; lead over sensing due to lead failure; sinus tachycardia; problems with environmental interference; and other unknown factors. Studies in which the incidence of ISTs has been examined have documented single, multiple, or repetitive shocks from a variety causes in ventricular ICDs. However, studies investigating atrial ICDs that cardiovert atrial fibrillation with a slow ventricular rate are no longer available and are beyond the scope of this review. Therefore, the topic of atrial ICDs will not be addressed.

\section{Overall Factors Contributing to IST}

The first large scale study reviewed by Grimm et al. (1992), retrospectively analyzed the incidence and causes of documented cases of spontaneous electrocardiography (ECG), and ICD discharges in the absence of VT and VF in 241 patients. During the follow-up period ( $24 \pm 20$ months), records of electrogram storage demonstrated that 54 of 241 patients $(22 \%)$ received a total of 132 spontaneous ICD charges in the absence of VT or VF. The researcher further found that the most frequent cause of these ISTs was AF with rapid ventricular response $(n=30$ patients $)$. ISTs caused by lead problems occurred in eight patients. The rest of events of IST were caused by generator malfunction VVI programming, and by T-wave oversensing. 
Nunain, Roelke, Trouton, Kim, Sosa-Suarez, and Brooks (1995) performed a descriptive study examining the problem(s) of third generation ICD therapy. One hundred and fifty-four patients with monomorphic sustained ventricular tachycardia (MSVT), VF, or syncope, with inducible VT not suppressed by antiarrhythmic drug therapy, and implanted with ICDs, were recruited for the study. In the mean follow-up period (15.3 \pm 9.7 months), 30 of 154 patients had non-thoracotomy lead systems. The $26 \%$ rate of IST was similar to that reported for an earlier generation (Grimm et al., 1992). Thirty-two patients ( $21 \%$ of subjects) received ISTs for either sinus tachycardia or AF with rapid ventricular response. In this study, AF remained the primary cause of IST, with lead problems as the second major cause $(n=3)$. Nunain et al. acknowledged that the success of ATP therapy could reduce the need for shock in the third generation ICD device.

Klein, Raitt, and Wilkoff (2003) expanded the number of subjects to evaluate the incidence and characteristics of arrhythmia events that triggered ICD therapy in the Antiarhythmics Versus Implantable Defibrillator (AVID) Trial. Four hundred ninety-two of 1016 participants in this trial were examined. The results demonstrated that inappropriate sensing, ICD malfunction, and electrode failure rarely triggered ICD therapy in the AVID trial. AF and other sustained ventricular tachycardia (SVT) were responsible for attempted therapy in 11 patients and for all 13 treated episodes. Patients who received IST were slighter younger $(63 \pm 11$ vs. $66 \pm 11, p<.05)$. Since approximately one-third of all patients in the AVID Trial received no syndrome preceding the delivery of the therapy, Klein et al. concluded that clinical or electrophysiologic parameters could not predict IST accurately. 
A prospective study, conducted by Russio, Nayak, Verdino, Springman, Tenfeld, et al. (2003), examined the occurrence of ICD shock events in 51 patients $\left(M_{\text {follow-up }}=16\right.$ months). IST occurred in four patients. Shock therapy was delivered for SVT in four patients; one IST delivery was related to AF; and one IST was related to T- wave oversensing. Russio et al. concluded that the low incidence of IST ( $8 \%)$ might be related to vigilant device programming. However, the follow-up period utilized in this study was limited.

Nanthakumar, Dorian, Paquette, Greene, Edwards, Heng, et al (2003) retrospectively analyzed the single chamber ICDs' recipients with a history of AF or NYHA Class I to identify patients most at risk for receiving inappropriate shock. Of 299 patients, 261 completed data for analysis. All received ICDs in 1990 using single chamber, third generation, tiered device therapy. Results confirmed that 116 of the 261 patients (44\%) received one or more inappropriate therapies and $73 \%$ of patients received inappropriate therapies within 2 years of receiving their device. The causes ISTs were: (a) $\mathrm{ST}=58(50 \%) ;(\mathrm{b}) \mathrm{AF}=38(33 \%) ;$ and $(\mathrm{c})$ noise events $=20(17 \%)$. Seventy-one percent of the patients received shocks within two years of device implantation. Significant predictors of inappropriate therapy with AF and NYHA Class 1 versus Class II- IV. Age, gender, and coronary artery bypass graft (CABG) did not increase the risk of receiving an IST. The type of medications taken upon hospital discharge was also not a predictor of events. Nanthakumar et al. supported the suggestion that ICD recipients with a previous history of AF should be considered "at risk" for the occurrence of IST. However, the hypothesis that NYHA Class I should not be considered a risk factor, since the development of IST remained unsupported. 
Recently, Rinaddi, Simmon, Bostock, Elliot, Bcknall, and Gill (2004) intended to assess whether the occurrence of IST would be reduced by the diagnostic enhancements of the ICD device. Rinaddi et al. retrospectively analyzed the data from 171 patients over 17 years of IST experience. Based on the records with full data $(n=155$ patients), results showed that IST occurred in 22 patients (14\%), predominantly for atrial arrhythmias (18 patients with IST for atrial flutter/AF or ST). The occurrence of IST in the remaining four patients was related to problems with lead fractures. The three independent predictors of IST identified by these researchers were pre-existing atrial tachyarrhythmias, co-existent medication therapy, and a single chamber device. Data also showed dilated cardiomyopathy (DCM) and high incidences of IST (50\%). AF incidence was also high $(80 \%)$ and in high proportion (78\%). Rinaddi et al. stated that the finding of increased coexistent medication therapy was not entirely clear, but might reflect poorer left ventricular functioning that is often associated with an enhanced use of medication therapy. Similarly, AF itself might be predisposed to ventricular arrhythmias. As for DCM patients, the researchers posited that the high incidences of IST were likely related to their increased incidence of $\mathrm{AF}$.

Most recently, a prospective study by Theuns, Klootwijk, Simoons, and Jordaens (2005). collected clinical and functional variables for each patient. This study evaluated whether clinical characteristics could predict inappropriate ICD therapy due to atrial tachyarrhythmias. The observations noted in this study were: (1) a history of atrial tachyarrhythmias is an independent predictor of inappropriate therapy; and (2) recurrent VT with a $\mathrm{C} 33 \mathrm{~L} \geq 350 \mathrm{~ms}$ that triggered device therapy was associated with an increased 
risk for first inappropriate therapy. However, this study was not thorough enough to adequately to address the clinical associates.

\section{Individual Factors}

\section{Lead Failure and Related Problems}

Dorwarth, Frey, Dugas, Matis, Fiek, Schmoeckel, et al. (2003) retrospectively analyzed the incidence and clinical presentation of transvenous ICD lead failures during long-term follow-up and their clinical mode of presentation $(n=261)$. These patients had a transvenous ICD lead systems that were implanted between 1990 and 1998. Seventy patients had an implantation site on the abdomen, whereas 191 patients had implantations on the pectoral site. Patients who had experienced lead dislodgement were excluded. The results demonstrated that 31 of 261 subjects' lead malfunction had inappropriate detection, with IST occurring in 19 of 31 patients who had received 1 to 11 shocks. A high number of malfunctions (48\%) was observed within the first year after device replacement due to battery depletion, with battery depletion occurring after $4.6 \pm .07$ years. Dorwarth et al. recommended that clinicians carefully monitor the lead status in any ICD recipient with a transvenous lead for more than four years.

\section{Lead Hyperpolarization}

Healy, Goyal, Browing, Robotis, Ramaswamy, Rofino-Nadoworany, et al. (2004) did a case study of another aspect of a lead problem. The patient involved did not experience any symptoms prior to being first shocked 16 months after implantation. He received the shock at a time when he was climbing the stairs. The initial shock occurred after an AF provoked an episode of VF. This VF was terminated by an appropriate shock, 
but due to lead hyperpolarization and $\mathrm{T}$ wave oversensing, the device continued to deliver five inappropriate therapies at 30 joules. The mechanism behind this phenomenon was unclear, but might have involved an interaction at the lead/myocardium interface at the time this patient climbed the stairs. Healey, et al. proposed that the mechanisms for proarrhythmic effects of shock might be caused by an increase in QT dispersion. Increasing sotalol from $40 \mathrm{mg}$ bid to $80 \mathrm{mg}$ bid resulted in no further shocks.

\section{Lead Connection: Header and Set Screw-Related Problems}

Picket, Saaverdr, Ali, Darbar, and Rottman (2004) reported four cases (i.e., three males and one female) of device malfunction due to the mechanical failure of a header connection within the a single device family over a limited time. The patient in Case 1 received one shock on the day after the procedure and 15 shocks occurred three days post implantation within one and a half hours. Repeated chest X-rays revealed an incomplete penetration of the right ventricular terminal pin in the header. Two ISTs occurred in Patient 3 as the left ventricular lead could not be placed due to increasing dyspnea at the time of implantation. After the device was replaced, no further problems were reported. The other two patients, as described by Picket et al., did not receive any ISTs. These cases shared a common element of defective connections between the header post and the right ventricular pace/sense terminal pin that required intervention and reconnection.

Picket et al. posited that such lead connection problems would increase as ICD devices became more complex.

\section{Double Counting}

Biventricular pacing emerged as a modality for the treatment of patients with heart failure. Combined biventricular pacers and ICDs offered treatment for heart failure 
as well as protection from a sudden cardiac death. Tachycardia detection in firstgeneration biventricular pacemaker-implantable cardioverter defibrillators (BiV ICD) occurred through both the right ventricular (RV) and left ventricular (LV) leads, creating the potential for inappropriate detection and therapies (Al-Ahmad, Wang, Homoud, Estes, and Link, 2004).

Case studies done by Schreieck, Zrenne, Kolb, Ndrepepa, and Schmitt (2001) and Liu, Villareal, Hariharan, Rasekh, and Massumi (2003) presented three patients who had all received IST from biventricular ICD therapy. Al-Ahmad, Wang, Homoud, Estes, and Link (2004) performed another study related to the problem of double counting. AlAhmad et al. retrospectively analyzed the ICD records from a group of 23 patients receiving biventricular ICD therapy. Within the follow- up period ( $3.7 \pm 2.6$ months), the results showed that 15 ISTs out of 33 shocks in five patients were caused by double sensing. All episodes resulting in shock occurred because of sinus tachycardia or a supraventricular tachycardia (SVT) higher than the upper-programmed pacing rate of the device with resultant AV conduction and double sensing of the non-paced ventricular depolarization. Al-Ahmad et al. concluded that double sensing of the R-wave was a common and clinically important cause of inappropriate ICD detection and shock in patients with biventricular ICDs. New generation devices with inappropriate detection in patients with a first-generation BiV ICD was common and often resulted in inappropriate ICD therapy. The most common mechanism of inappropriate detection was double counting, often creating the need for additional procedures. Although devices in which tachycardia detection occurred only through the RV lead were now available, RV/LV output and double counting should therefore not occur. However, close follow-up of the 
patients who received a first-generation BiV ICD was necessary (Chugh, Scharf, Hall, Cheung, Good, Horwood, et al., 2005)

\section{Generator Malfunction Issues}

Generator malfunction constitutes another type of device limitation that could also cause an inappropriate shock. De Meester and Gilles (2001) reported a case study of IST that related to the ICD malfunction caused by excessive defibrillation of charge time twice ( 22 seconds and 19 seconds). Suspected were the gradual decline in battery voltage and increase of battery resistance, and the consequence of excessive charge time of the electric capacitors device was affected by highly variable and ineffective capacitors. Therefore, a new generator was implanted. De Meester and Gilles stated that, to avoid similar events from recurring, long-term follow-up would be needed to investigate the predisposing factors related to a malfunction of the capacitor's elements. Because of this potentially serious effect, the manufacturer recommended that ICDs with a charge time longer than 14 seconds should be monitored every month. They also suggested that, if a charge time exceeded 60 seconds, an immediate replacement was needed.

\section{Diaphgram Myopotential}

Three case studies were reported by Peters, Cooklin, Brockman, Steven, Shorofsky, \& Michael, (1998). The patient in case 1 had received all asymptomatic shocks, which were not triggered by VT. But noise and oversensing were present during normal sinus rhythm (NSR) at a moment when the subject was performing the Valsalva maneuver. After decreasing the sensitivity in the device, the researchers noted that no further shocks occurred in the ensuing month of follow-up. Peters et al. stated that in all three cases, the lead was initially positioned in the right ventricular apex. It is presumed 
IST in patients with ICDs 30

that the sensing of diaphragmatic potentials was directly related to the proximity of the lead to the diaphragm. Peter et al. also recommended that the possibility of sensed DMP should be considered at the time of ICD implantation, especially during ventricular pacing, so that the appropriate preventive measures can be taken.

In a larger prospective study, Schulte, Sperzel, Carleson, Dursh, \& Erdogan, et al (2001) investigated the incidence of diaphragmatic myopotential (DMP) in a cohort of 384 ICD recipients from 1991 to 1999 . One hundred and thirty-nine nonadequate episodes of arrhythmia due to the oversensing of diaphragmatic myopotentials were observed in 33 out of 384 patients. Eleven out of these 33 patients had a total of 32 high energy shocks. The majority of nonadequate arrhythmia detections were during intrinsic bradycardia pacing. Electrical lead failure was ruled out in every patient. In $90 \%$ of ICD recipients provided with programmable maximal sensitivity $(n=16)$, the reduction of maximum sensitivity was effective in preventing further episodes of nonadequate arrhythmia deduction. Schulte et al. recommended that the clinical use of provocation maneuvers to examine the oversensing of DMP, (i.e., using the induction of DMP oversensing to distinguish far field oversensing from electrical lead failure,) can prevent an unnecessary surgical lead revision.

\section{Electromagnetic Interference}

Anfinsen, Bernsten, Kongsgaard, \& Amlie (2002) reported the experience of an ICD recipient who had been implanted with an ICD endocardial lead post MI with VF. Two ISTs occurred during an MRI of the brain in this patient. These authors proposed that electromagnetic noise induced during the MRI may be detected as VF and 
subsequently cause IST. Anfinsen et al. Suggested that clinicians should consider inactivating the ICD before an MRI procedure.

Anifinsen et al. went on to describe EMI occurring in four other patients with ICDs. Patient A received one shock while she was cleaning a lamp that connected to a $230 \mathrm{~V} 50 \mathrm{~Hz}$ alternating current. Patient B received an IST when he was using a vibrator for genital and anal stimulation. Patient $C$ experienced two ISTs while being treated by electronic muscle stimulation of the gluteal region. Patient $\mathrm{D}$ was using a percussion drill when he experienced two episodes of VF detection during sinus rhythm.

The incidence of IST caused by EMI has been estimated as $<1 \%$ per patient/per year (Kolb, Zrenner, and Schmitt, 2001). However, some episodes may have gone undetected. Thus, the overall incidence of EMI might be underestimated in the literature. The improvement of EMI detection algorithms and advances in lead technology are necessary to minimize the risk of EMI-related IST in ICD patients.

The interference between ICD function and the use of a washing machine was documented by Chan and Ho (2005). These authors also reported an instance of IST occurring when a subject wore a pair of cotton gloves to operate a power drill during a rainy day. Therefore, Chan and Ho suggested that EMI due to $50 \mathrm{~Hz}$ alternating current leak could be avoided by giving detailed advice on the handling of electrical appliances to $\mathrm{ICD}$ recipients.

\section{Drug Interactions}

The concomitant administration of antiarrhythmic drug therapy remains common in patients with ICD. The potential influence of antiarrhythmic drugs on the defibrillation threshold (DFT) is the most significant issue. Class III agents (except amiodarone) can be 
safely administered in conjunction with ICD patients as long as the interaction between these therapeutic modalities is monitored (Sergo, \& Gerard, 1995).

Due to the psychological impact of ICD therapy, patients with these devices often had symptoms of anxiety or depression (Dougherty, 1995, Burg, Lampert, Joska, Batsford, \& Jain, 2004). Pickworth, Votolato, and Raman (2004) reported a 35-year-old woman with depression. After implantation, the ICD was tested by delivering a shock on the $\mathrm{T}$ wave to induce VF. It was not terminated by one 15 joules and one 20 joules shock, but terminated by an additional seven external shocks of 360 joules. After evaluating the patient's drug regimen, a suspected drug to device interaction was discovered between Venlafaxine and ICD. After discounting Venlafaxine, an antidepressant with cardiac sodium, channel blocking activity was identified as a potential contributor to her elevated defibrillation threshold. The ICD was able to successfully defibrillate the patient. Carners et al. (2004) suggested that clinicians should be aware of this potential adverse drugdevice interaction. Further studies are needed to determine the clinical significance of Venlafaxine therapy in patients with ICDs.

In a case reported by Mcbride, \& Klucger (2004), an ICD recipient consumed two to three doses of Metabolife 356, a dietary weight loss supplement. The patient received four ISTs within 3 days. Device interrogation revealed atrial tachycardia. The patient stopped taking Metabolife 356 and took increasing doses of Sotalol instead. The patient remained event free for 18 months. The researcher suspected that the Metabolife 356 induced atrial tachycardia resulted in multiple discharges. This author proposes that ICD recipients concomitantly consuming alternative pharmacotherapy may have an enhanced risk of inappropriate ICD functioning. 
IST in patients with ICDs 33

\section{Clinical Characteristics and Other Factors}

Authorities propose that IST is most often the result of SVT, lead/device malfunction, or oversensing. Other situations leading to the occurrence of IST have been reported as well (Healy, Ngarmukos, and Rosenthal, 2002).

Healy, Ngarmukos, and Rosenthal (2002) described a case experiencing an IST associated with improper timing. This 58 year-old man with a history of ICM underwent ICD implantation after having an EPS positive for inducible SMVT. One IST occurred at one week post implantation. Electrograms revealed that a run of NSVT had caused the ICD to charge. The device appropriately detected the rhythm abnormality and charged. However, after charging, a premature ventricular contraction (PVC) with a short coupling interval was detected during the second look window and a shock was delivered to the patient while in sinus rhythm. Thus, Healey et al. stressed that while algorithms are being developed to deliver appropriate therapy for life-threatening ventricular arrhythmias, an algorithm that allowed for continued sensing during the charge period might have saved this particular patient.

Recently, it has been proposed that a congenital short QT interval is associated with an increased risk for arrhythmias and SCD (Schimpf et al, 2003). At present, the ICD is the only therapeutic option. Schimpf et al. recruited five patients from two unrelated European families who had structurally normal hearts, excessively shortened QT intervals, and strong positive family history of SCD. ICDs were placed for primary and secondary prevention. Mean QT intervals were $252 \pm 13 \mathrm{~ms}$ (QTc $287 \pm 13 \mathrm{~ms}$ ). In the follow-up $30 \pm 26$ days, Schimpf et al. observed that three of five patients received ISTs for T wave oversensing. After reprogramming their generators of ICDs by lowering 
sensitivities, no further episodes of IST were noted. Schimpf et al. concluded that an increased risk for IST is inherent, due to the detection of short-coupled and prominent T waves.

Idiopathic VF patients had a high recurrence rate of ventricular arrhythmias. ICD prevented SCD from this population; the clinical outcome of the ICD recipients with solely a diagnosis of Idiopathic VF was lacking. Champagne, Geelen, Philippon, and Brugada, (2005) conducted a prospective cohort study (from 1992 to 2000) to examine the clinical and electrophysiological characteristics of consecutive SCD survivors from idiopathic VF. In this study, after excluding those patients with LQTS, Brugada syndrome, right ventricular dysplasia and no history of CAD from 445 ICD recipients, 18 patients with idiopathic VF were studied. Six participants had syncope associated with self terminated TdP or VF, and 12 subjects survived an episode of SCD with VF. All of the subjects had left ventricular ejection fraction of $>50 \%$ and a mean age of 42 (ranging from 20 to 70 ). At the mean follow-up at $41 \pm$ months, 7 out of 18 patients received a total of 27 shocks, and 8 of $18(44 \%)$ subjects received IST for a total 21 discharges. The causes included AF in 12 of 21 (57\%) episodes in 14 patients (mean age $53 \pm 14$ years); sinus tachycardia in 6 of 21 episodes in 4 patients (mean age of $31 \pm 13$ years); lead malfunction 3 of 21 episodes in 2 patients (mean age unknown); and 6 of 21 episodes in 2 patients had experienced IST from AF. Data also demonstrated that the presence of the ICD prevented SCD from idiopathic VF, and only treated the final manifestation of unknown diseases. IST remained a major concern in this young population. 


\section{Death Events Related to Inappropriate Shock Therapy}

Messali, Thomas, Chauvin, Conmel and Leenhardt (2004) reported that the cause of death of one ICD recipient was related to IST. This patient was a 49 year-old man, with a 15 -year history of NIDCM and an LVEF of $40 \%$. The patient had a history of two cases of SCD and DCM in his immediately family. A syncopal SMVT was performed in 1991, with an initial ICD implantation in 1991 in the abdominal site. The generator was replaced in 1995 and in 2000, but the same atrial and ventricular leads from the original ICD implantation were retained. This patient received six shocks and experienced SCD in 2000. Data storage of the fatal event showed an episode of ventricular oversensing during sinus rhythm that was improperly designated as VF because of some short cycle lengths $<$ $300 \mathrm{~ms}$. This false detection triggered the first shock as well as five subsequent shocks within two minutes. The sixth shock induced a true, untreatable VF. Inappropriate shocks were delivered due to noise oversensing originating from a ventricular lead with an insulation defect. In the interrogation of the device, it was also revealed that the patient had experienced an IST nine days earlier due to the same type of oversensing and multiple NSVT that might have been oversensing in the 12 days before death. Messali et al. posited that the event of noise oversensing could be caused by an insulation defect of the ventricular lead that was caused by prolonged used and repeated episodes of shock. However, other studies have demonstrated that oversensing could have occurred without structural lead failure (Dorwarth, et al, 2003). Therefore, the abdominal location and coaxial body design may be predictors for long-term structural failure of the ventricular lead. Messali et al. emphasized the need for careful follow-up for patients with ICDs and the performance of interrogation as soon as possible following a shock delivery. 
A recent tragic event occurred, caused by a generator malfunction, to a 21 yearold college student with $\mathrm{HCM}$, according to a manufacturer's report. An autopsy revealed no clinically significant pathology beyond a massive left ventricular hypertrophy. An ICD was shown to be almost successful in preventing SCD for this young man. When the manufacturer analyzed the ICD, it was revealed that the device had shortcircuited internally while trying to deliver high voltage therapy, thereby permanently disabling itself. Its memory had been destroyed, making the time of failure impossible to pinpoint (Gornic, Hauser, Almquist, Maron, 2005; Steinbrook, 2005). Since this defect was not detected at the patient's previous regular follow-up, the safety and the reliability of these life-saving devices triggered a broad discussion. The FDA and Heart Rhythm Society will plan to develop the guidelines regarding ICD recalls for manufacture notification standards and will decide when to replace the ICD devices.

\section{Summary and Conclusions}

Despite the rapid evolution of the ICD device and algorithms designed to reduce IST, the reported incidence of IST ranges from $5 \%$ to $20 \%$ and continues to be a major problem associated with the use of ICD. Although spurious discharges are most commonly caused by supraventricular arrhythmias, especially AF, IST can be triggered by device malfunction, such as lead failure due to battery depletion, and problems related to header and set screw connections, double counting, lead hyperpolarization and generators. Other factors, such as an oversensing of diaphragmatic myopotential, electromagnetic interference, and interactions between antiarrythmic medications and the ICD device are also frequently reported by researchers. 
There is also a growing consensus that structural heart diseases, such as ischemic cardiomyopathy and heart failure, which induce the development of AF, contribute to the occurrence of IST. In addition, non- structural heart diseases, such as T wave oversensing, occurred in patients with short QT syndrome. In some situations, researchers suspected the underlying pathology may contribute to IST, although the exact nature of the relationship of cardiac pathology to IST remains to be explored.

As the above literature review demonstrates, current documentation of the IST phenomenon in ICD patients is limited to either case studies or descriptive research investigations with mostly small numbers of subjects. Hence, the knowledge base in this area is at an initial stage. While it is a definite limitation that the proposed study is based on single-case studies and limited research, it is an appropriate next step in the development of knowledge to examine further the factors which experts suspect may play a significant role in contributing to the occurrence of IST. Table 2 refers to the risk factors of IST in the above studies.

Therefore, given the available evidence regarding the complex factors contributing to IST, the researcher has examined the incidence of appropriate shock and inappropriate shock occurrence and has investigated the clinical predisposing factors of inappropriate shock in a group of ICD recipients from a major medical center located in Southern California, which also serves as a tertiary referral hospital. 
Table 2

Inappropriate Shock Therapy Events in ICD Studies with Varying Criteria (Studies are Chorological Order)

\begin{tabular}{|c|c|c|c|}
\hline $\begin{array}{l}\text { Author(s) } \\
\text { /year }\end{array}$ & $\begin{array}{l}\text { Subjects } \\
(\mathrm{N}=\text { Total })\end{array}$ & $\begin{array}{l}\text { Research } \\
\text { Design }\end{array}$ & Finding (s) R/T IST \# \& Cause(s) \\
\hline $\begin{array}{l}\text { Grimm } \\
\text { et al } / 1992\end{array}$ & $\mathrm{~N}=241$ & $\begin{array}{l}\text { Retrospective } \\
\text { Analysis }\end{array}$ & $\begin{array}{l}\text { 54 of } 241 \text { patients (22\%) received a total } 132 \text { spontaneous ICD charges to the absence of VT } \\
\text { or VF } \\
\text { AF RVR: }\end{array}$ \\
\hline $\begin{array}{l}\text { Nunain } \\
\text { et al } / 1995\end{array}$ & $\mathrm{~N}=154$ & $\begin{array}{l}\text { Descriptive } \\
\text { study }\end{array}$ & $\begin{array}{l}\text { - IST experience : } 36(28 \%) \text { Patients } \\
\text { - AF }: 32(21 \%) \text { SVT (AF or Sinus tachycardia) excess autogain in } 2 \text { patients. } \\
\text {-Lead problem : } 1\end{array}$ \\
\hline $\begin{array}{l}\text { Nanthakumar } \\
\text { et al } / 2003\end{array}$ & $\mathrm{~N}=261$ & $\begin{array}{l}\text { Retrospective } \\
\text { study }\end{array}$ & $\begin{array}{l}\text { 116/261 patients received IST } \\
\text { - Causes: } \\
\text { - ST: } 58(50 \%) \text {, } \\
\text { - AF: } 38(33 \%) \\
\text { - Noise events: } 20(17 \%) \\
\text { - Predictors of increasing risk of receiving IST } \\
\text {-Previous Hx of AF \& } \\
\text { NYHA FcI received single chamber had high risk of develop IST 2-4 =1.3:1 } \\
\text {-Age, sex, \& CABG did not increase the risk of receiving IST }\end{array}$ \\
\hline
\end{tabular}




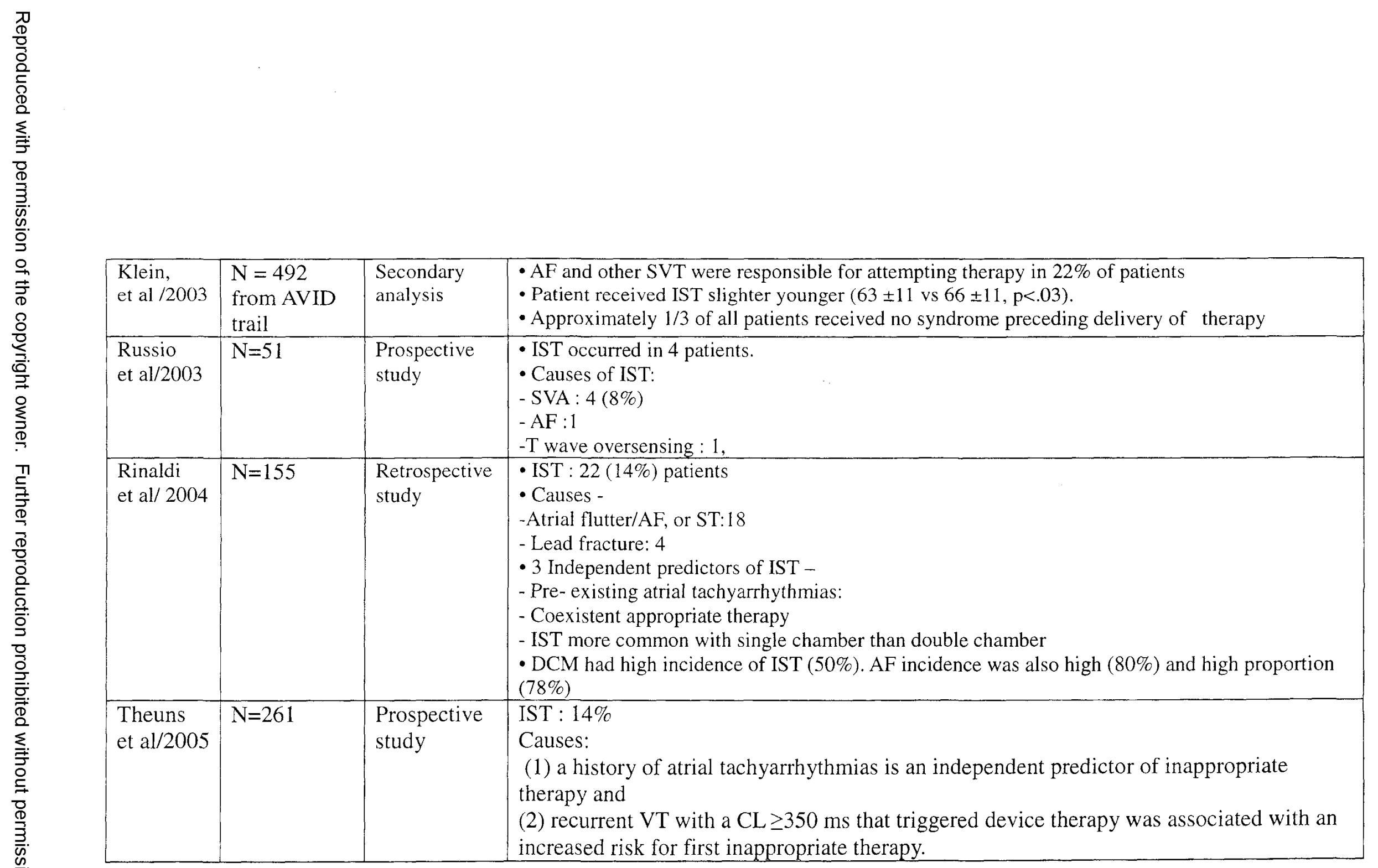


B. Inappropriate Shock Therapy Events in ICD Studies with Varying Criteria /Lead Problems

\begin{tabular}{|c|c|c|c|}
\hline $\begin{array}{l}\text { Author(s) } \\
\text { /year }\end{array}$ & $\begin{array}{l}\text { Subjects } \\
(\mathrm{N}=\text { total) }\end{array}$ & $\begin{array}{l}\text { Research } \\
\text { Design }\end{array}$ & Finding (s) R/T IST \# \& Cause(s) \\
\hline $\begin{array}{l}\text { Dorwarth } \\
\text { et al/ } 2003\end{array}$ & $\mathrm{~N}=261$ & $\begin{array}{l}\text { Retrospective } \\
\text { analysis }\end{array}$ & $\begin{array}{l}\cdot 31 / 261 \text { subjects lead malfunction had inappropriate detection } \\
\cdot \text { IST occurred } 19 / 31 \text { patients } \\
\cdot 3 \pm(1-11) \text { shocks /patient } \\
\text { X- ray did not show lead fracture in any of patient. Only one case had subclavian crush } \\
\text { syndrome. S/P the association with battery depletion secondary to old lead ( }>4 \text { years) }\end{array}$ \\
\hline $\begin{array}{l}\text { Healey } \\
\text { et al /2004 }\end{array}$ & $\mathrm{N}=1$ & Case Report & $\begin{array}{l}\text { - Initial IST AF } \\
\text { - the subsequently } 6 \text { ISTs: } T \text { wave oversensing secondary to lead hyperpolarization. }\end{array}$ \\
\hline $\begin{array}{l}\text { Pickett III } \\
\text { et al } / 2004\end{array}$ & $\mathrm{~N}=4$ & Case report & $\begin{array}{l}\text { Case 1: } 15 \text { shocks, -ray revealed incomplete penetration to the RV terminal pin in the header. } \\
\text { Case 2: no shock although it was found that the terminal pin penetration beyond the set screw } \\
\text { Case 3: Case 3- } 2 \text { ISTs due to the LV lead could not placed because of increasing dyspnea at } \\
\text { the time of implantation } \\
\text { Case } 4 \text {-no shock, terminal pin failed to extend beyond the set screw. } \\
\text { These cases shared a common element of defective connections between the header post and } \\
\text { the right ventricular pace/sense terminal pin that required intervention and reconnection }\end{array}$ \\
\hline
\end{tabular}

C. Double Counting

\begin{tabular}{|l|l|l|l|}
\hline $\begin{array}{l}\text { Author(s) } \\
\text { /year }\end{array}$ & $\begin{array}{l}\text { Subjects } \\
(\mathrm{N}=\text { total })\end{array}$ & $\begin{array}{l}\text { Research } \\
\text { Design }\end{array}$ & Finding (s) R/T IST \# \& Cause(s) \\
\hline $\begin{array}{l}\text { Schreieck } \\
\text { et al } / 2001\end{array}$ & $\mathrm{~N}=1$ & Case study & An IST due to double detection of ventricular premature beats. \\
\hline $\begin{array}{l}\text { Liu. } \\
\text { et al } / 2003\end{array}$ & $\mathrm{~N}=3$ & Cases study & $\begin{array}{l}\text { Case 1 - one IST occurred at 3 weeks after implantation } \\
\text { Case 2 - 4 ISTs occurred during 3 days after 2 weeks implantation. } \\
\text { Case 3 - one IST occurred 2 months after implantation }\end{array}$ \\
\hline $\begin{array}{l}\text { Al-Ahmad } \\
\text { et al/ 2004 }\end{array}$ & $\mathrm{N}=23$ & $\begin{array}{l}\text { Retrospective } \\
\text { study }\end{array}$ & $\begin{array}{l}\text { 15 IST /33 IST episodes in 5 patients } \\
\text { 7/33 }(21.7 \%) \text { due to double sensing. } \\
\text { 4 patients (17.4\%) had aborted shocks due to double sensing }\end{array}$ \\
\hline
\end{tabular}




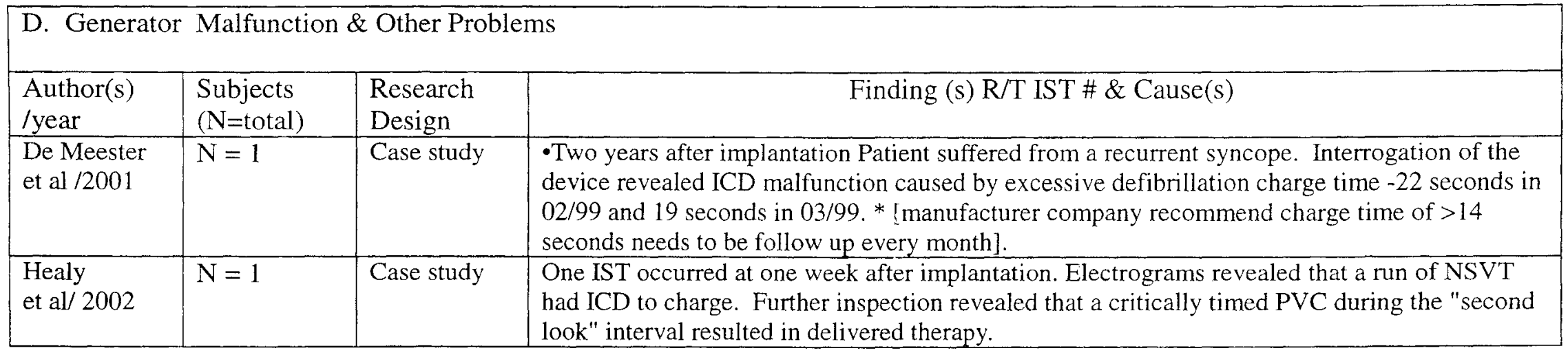

\section{E. Oversensing of Diaphragmatic Myopotentials}

\begin{tabular}{|l|l|l|l|}
\hline $\begin{array}{l}\text { Author(s) } \\
\text { /year }\end{array}$ & $\begin{array}{l}\text { Subjects } \\
(\mathrm{N}=\text { total })\end{array}$ & $\begin{array}{l}\text { Research } \\
\text { Design }\end{array}$ & Finding (s) R/T IST \# \& Cause(s) \\
\hline $\begin{array}{l}\text { Peters } \\
\text { et al } / 1998\end{array}$ & $\mathrm{~N}=3$ & Case report & $\begin{array}{l}\text { Case 1-All several asymptomatic shocks were not triggered by VT. } \\
\text { noise \& oversensing during NSR with deep inspiration \& valsalva maneuver. } \\
\text { Case 2 - Received several shocks during AF \& multiple arrhythmia detection's during NSR at } \\
\text { the time of patient's defecating. } \\
\text { Case 3 An asymptomic shock was demonstrated during valsalva maneuver }\end{array}$ \\
\hline $\begin{array}{l}\text { Schulte } \\
\text { et al/2001 }\end{array}$ & $\mathrm{N}=384$ & $\begin{array}{l}\text { Prospective } \\
\text { study }\end{array}$ & $\begin{array}{l}\text { 139 non adequate episodes of arthythmia due to oversensing of diaphragmatic myopotentials } \\
\text { were observed in 33 patients. } \\
11 / 33 \text { patients had a total 32 high energy shock occurred. ***The oversensing of } \\
\text { diaphragmatic myopotential to be distinguished from lead failure. }\end{array}$ \\
\hline
\end{tabular}




\begin{tabular}{|c|c|c|c|}
\hline \multicolumn{4}{|c|}{ F. Interferences with Environment } \\
\hline $\begin{array}{l}\text { Author(s) } \\
\text { /year }\end{array}$ & $\begin{array}{l}\text { Subjects } \\
\text { (N=total) }\end{array}$ & $\begin{array}{l}\text { Research } \\
\text { Design }\end{array}$ & Finding (s) R/T IST \# \& Cause(s) \\
\hline $\begin{array}{l}\text { Groh } \\
\text { et al /1999 }\end{array}$ & $N=169$ & $\begin{array}{l}\text { Post only } \\
\text { design }\end{array}$ & $\begin{array}{l}\text { - G1: No any negative response in routine exposure ( } 10-15 \text { seconds) } \\
\text { - G2: } 3 \text { subjects experienced inappropriate tachyarrhythmia detection, } \\
\text { - G3: } 19 / 126 \text { showed evidence of oversensing. } \\
\text { - no ICD reprogramming was observed in any of the ICDs in all } 3 \text { groups. }\end{array}$ \\
\hline $\begin{array}{l}\text { Kolb } \\
\text { et al } / 2001\end{array}$ & $\begin{array}{l}\mathrm{N}=4 / 341 \\
\text { patients }\end{array}$ & $\begin{array}{l}\text { Retrospective } \\
\text { Study }\end{array}$ & $\begin{array}{l}\text { Case } 1 \text {, one shock delivered at the time she cleaned the lamp that connect to } 230 \mathrm{~V} \text {, } \\
50 \mathrm{~Hz} \text { alternating current. } \\
\text { Case 2, one IST when using a vibrator for genital and anal stimulation } \\
\text { Case } 3 \text {, was treated by electronic muscle stimulation of the gluteal region, EMI lead to } \\
\text { detection of VF and response shock twice. } \\
\text { Case } 4,2 \text { episodes of detectionof VF during sinus rhythm with a normal rate recorded by } \\
\text { device at the time patients was using a percussion drill. }\end{array}$ \\
\hline $\begin{array}{l}\text { Anfinsen } \\
\text { et al } / 2002\end{array}$ & $\mathrm{~N}=1$ & Case study & 2 ISTs occurred during brain MRI procedure. \\
\hline $\begin{array}{l}\text { Kolb } \\
\text { et al/2002 }\end{array}$ & $\mathrm{N}=1$ & Case study & $\begin{array}{l}\text { a defibrillation shock without warning symptoms at the moment patient touched washing } \\
\text { machine. } \\
\text {-Hemodynamic instability.Ruled out sensing problems, No myopotentials; } \\
\text {-Rule out lead and pulse generator malfunction by the evidence of X-ray and interrogation data } \\
\text { (history). -S/P washing machine was not properly grounded. }\end{array}$ \\
\hline $\begin{array}{l}\text { Chan } \\
\text { et al } / 2005\end{array}$ & $\mathrm{~N}=2$ & Case study & $\begin{array}{l}\text { Case } 1 \text {, received one IST at the time he operating power drill while it was raining and he wore } \\
\text { a pair cotton gloves. } \\
\text { Case } 2 \text {, received one IST while He used his wet hand to touch the old washing } \\
\text { machine, which current was leaked. }\end{array}$ \\
\hline
\end{tabular}




\begin{tabular}{|c|c|c|c|}
\hline $\begin{array}{l}\text { Author(s) } \\
\text { /year }\end{array}$ & $\begin{array}{l}\text { Subjects } \\
(\mathrm{N}=\text { Total) }\end{array}$ & $\begin{array}{l}\text { Research } \\
\text { Design }\end{array}$ & Finding (s) R/T IST \# \& Cause(s) \\
\hline $\begin{array}{l}\text { Capoferri } \\
\text { et al } / 2004\end{array}$ & $N=100$ & $\begin{array}{l}\text { Prospective } \\
\text { observation } \\
\text { study }\end{array}$ & $\begin{array}{l}\text {-19(19\%) patients experienced inappropriate therapy. } \\
12 / 19 \text { received shock. } \\
\text { - Causes of IST : Atrial tachycardia : } 8 ; \text { Sinus tachycardia : } 9 ; \text { T wave oversensing : } 2 \text {. } \\
\text { - No significant difference of the incidence rate of IST in primary prevention and secondary } \\
\text { prevention groups. }\end{array}$ \\
\hline $\begin{array}{l}\text { Carnes } \\
\text { et al/2004 }\end{array}$ & $\mathrm{N}=1$ & Case study & $\begin{array}{l}\text { Venlafaxine, an antidepressant with cardiac sodium channel blocking activity, was identified as } \\
\text { a potential contributor to patient's elevated defibrillation threshold. }\end{array}$ \\
\hline $\begin{array}{l}\text { Mcbride } \\
\text { et al/2004 }\end{array}$ & $\mathrm{N}=1$ & Case study & $\begin{array}{l}\text { After consuming } 2 \text { to } 3 \text { doses of Metabolife } 356 \text { (a dietary weight loss supplement), patient } \\
\text { received } 4 \text { IST within } 3 \text { days. Device interrogation revealed atrial tachycardia. }\end{array}$ \\
\hline
\end{tabular}




\begin{tabular}{|c|c|c|c|}
\hline $\begin{array}{l}\text { Author(s) } \\
\text { /year }\end{array}$ & $\begin{array}{l}\text { Subjects } \\
(\mathrm{N}=\text { total) }\end{array}$ & $\begin{array}{l}\text { Research } \\
\text { Design }\end{array}$ & Finding (s) R/T IST \# \& Cause(s) \\
\hline $\begin{array}{l}\text { Schimpf } \\
\text { et al/ } 2003\end{array}$ & $\begin{array}{l}\text { - } \mathrm{N}=5 \text { from } \\
\text { two families } \\
\text { - structurally } \\
\text { normal hearts, } \\
\text { - excessively } \\
\text { shortened QT } \\
\text { intervals \& } \\
\text { positive } \\
\text { family Hx of } \\
\text { SCD. }\end{array}$ & $\begin{array}{l}\text { Case } \\
\text { study }\end{array}$ & $\begin{array}{l}\text { - } 3 \text { of } 5 \text { patients received ISTs for T wave oversensing. } \\
\text { - Schimpf et al concluded that increased the risk for IST is inherent due to the } \\
\text { detection of short-coupled and prominent } T \text { wave. }\end{array}$ \\
\hline $\begin{array}{l}\text { Glikson } \\
\text { et al/2004 }\end{array}$ & $\begin{array}{l}-\mathrm{N}=82 \\
- \text { stable VT } \\
\text { - mean age : } \\
66.2 \pm 11.3 \\
\text { - stable VT }\end{array}$ & $\begin{array}{l}\text { Retrospecti } \\
\text { ve } \\
\text { analysis }\end{array}$ & $\begin{array}{l}\text { - } 29(35 \%) \text { patients had at least one IST. } \\
\text { - Hemodynamically stable VT were at considereable risk for subsequent unstable VT } \\
\text { - No description of the events of IST. But Glikson et al suggested that degree of the structure } \\
\text { of heart disease may be as or more important than absence or presence of arrhythmia } \\
\text { symptoms for predicted death. }\end{array}$ \\
\hline $\begin{array}{l}\text { Champagne } \\
\text { et al / } 2005\end{array}$ & $\begin{array}{l}\mathrm{N}=18 \\
\text { idiopathic VF } \\
\text { out of } 445 \\
\text { ICD } \\
\text { recipients }\end{array}$ & $\begin{array}{l}\text { Prospective } \\
\text { cohort } \\
\text { study }\end{array}$ & $\begin{array}{l}\text { 7/18 patients received a total of } 27 \text { shocks. } \\
\text { - } 8 / 18(44 \%) \text { subjects received IST for a total } 21 \text { discharges. } \\
\text {-AF: } 12 / 21(57 \%) \text { episodes in } 14 \text { patients, these patients are older. mean age } 53 \pm 14 \text {, } \\
\text {-Sinus tachycardia }: 6 / 21 \text { episodes in } 4 \text { patients with a mean age of } 31 \pm 13 \text { years. } \\
\text {-Lead malfunction : } 3 / 21 \text { episodes in } 2 \text { patients. } \\
\text {-Unknown : } 6 / 21 \text {, episodes in } 2 \text { patients \& had experienced IST for AF. }\end{array}$ \\
\hline
\end{tabular}


I. Specific Clinical Characteristics

\begin{tabular}{|l|l|l|l|}
\hline $\begin{array}{l}\text { Author(s) } \\
\text { year }\end{array}$ & $\begin{array}{l}\text { Subjects } \\
\text { (N=Total) }\end{array}$ & $\begin{array}{l}\text { Research } \\
\text { Design }\end{array}$ & Finding (s) R/T IST \# \& Cause(s) \\
\hline $\begin{array}{l}\text { Messali } \\
\text { et al } / 2004\end{array}$ & $\mathrm{~N}=1$ & Case study & $\begin{array}{l}\text { 6 shocks on 03/31/00, SCD on 06/29/00. } \\
\text { Data storage of fatal event showed an episode of ventricular oversening during sinus rhythm } \\
\text { that was designed as VF because of some short cycle lengths }<300 \mathrm{ms.} \mathrm{This} \mathrm{false} \mathrm{detection} \\
\text { triggered the first shock and the five subsequent shocks within 2 minutes, the } 6^{\text {th }} \text { shock induced } \\
\text { atrue VF that could not be treated because the end of therapeutic procedure had been reached. }\end{array}$ \\
\hline $\begin{array}{l}\text { Steinbrook } \\
12005\end{array}$ & $\mathrm{~N}=1$ & Case Study & $\begin{array}{l}\text { Subject died suddenly, EGM revealed the device had short-circuited internally while } \\
\text { trying to deliver high voltage therapy, it was permanently disabled. More over, its } \\
\text { memory had been destroyed, making the time of failure impossible to pinpoint. }\end{array}$ \\
\hline
\end{tabular}

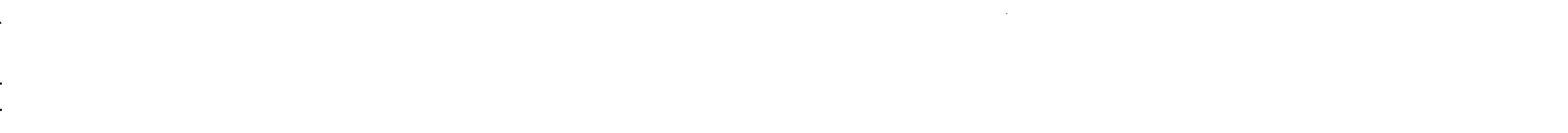


IST in patients with ICDs 46

\section{CHAPTER III \\ METHODOLOGY \\ Research Design}

This five-year retrospective study was designed to analyze the incidence of appropriate and inappropriate shock and the clinical predictors for inappropriate shock in a group of ICD recipients from a university medical center. This study was carried out by reviewing ICD interrogation records and medical charts.

A retrospective method was chosen primarily because the knowledge base regarding factors that contribute to IST is currently at the descriptive level. It is known that the events contributing to IST include multiple intrinsic and extrinsic factors; however, there are many gaps in current knowledge regarding these clinical characteristics and their associations to IST. A retrospective method examining 5 years of patient data was used to capture a variety of salient factors related to the incidence of IST. However, this investigation may still have been confounded by the possibility of two problems: first, that the observed time period was too short to provide enough information; and second, that rapidly changing technological and pharmaceutical developments in devices and treatments may have rendered data difficult to evaluate on a cohort basis. With these possible problems in mind, the 
current study was based on data gathered over a five-year period, a moderate amount of time that can provide sound results for analyzing the maximum strengths and minimal weaknesses of a cohort.

\section{Research Setting}

This study was conducted at the Arrhythmia Clinic at the University of Medical Center in Southern California, USA. This university medical center serves the surrounding metropolis and participates as a tertiary, regional, referral center for the area's cardiovascular patients. Although the majority of patients were local residents at the time of ICD implantation and follow-up, some patients came from areas outside of the region. Therefore, this study has the benefit of being based on results from a diverse group of participants. This hospital has well established systems in its Arrhythmic Clinic. Patients who undergo ICD implantation receive follow-up care in the clinic, including interrogation procedures to examine the ICD device function. Interrogation allows electrophysiologists to determine effects from specific forms of electrical shock therapy that a patient received since the previous clinic visit. Lead integrity and battery status are also checked. The ICD device can then be adjusted to optimize detection and therapy parameters. Most ICDs record the patient's electrocardiographic tracing at the time of arrhythmia detection. This 
IST in patients with ICDs 48

the patient's electrocardiographic tracing at the time of arrhythmia detection. This information can then be analyzed at follow-up visits to determine the nature of the arrhythmia and the efficacy of the electrical therapy that was given.

The cardiac electrophysiologist, along with a trained technician and/or a cardiovascular nurse, typically conducts an interrogation once every three months. An interrogation is also conducted as the device approaches elective replacement, as well as at any time of symptomatic events (e.g., shock occurrence).

Sample

\section{Criteria for Sample Inclusion/Exclusion}

The target group consisted of ICD recipients who underwent follow-up examinations in the Medical Center Arrhythmic Clinic from January of 2000 to May of 2005.

The following inclusion criteria were utilized for this study:

1) Persons age 18 and above who had received an ICD and attended one or more ICD clinic visits at the medical center;

2) The documented occurrence of an appropriate shock (i.e., a shock delivered in the presence of VT or VF), and/or an inappropriate shock (i.e., a shock delivered in the absence of VT or VF). 
2) An incomplete chart record regarding pertinent study data.

\section{Data Collection}

\section{Data Collection Instrument}

The data collection form was designed by the researcher and reviewed by two electrophysiologists for content validity (see Appendix D). Each item was designed to obtain appropriate demographic information and clinical characteristics. In addition, indications for ICD implantation, clinical history, underlying diseases, and prescribed medications were recorded. Device information and the history of shock events were integrated as well.

Validity and Reliability of the ICD Records and Charts

Records from medical charts and ICD records offer objective evidence (Eder, Fullerton, Benroth, \& Lindsy, 2005). Descriptions of events reported by patients and their families were recorded by an examining physician shortly after the actual IST events. Therefore, error variance in research conclusions should be minimized by the short time interval between the occurrence of the event and its report.

To minimize the variability and increase the precision of measurements, all data were collected by the researcher and confirmed by an electrophysiologist. Thus, concerns of inter-rater reliability have been minimized. 
concerns of inter-rater reliability have been minimized.

\section{Data Collection Procedures}

Following appropriate IRB approval from the major university medical center in Southern California that served as the data collection site, the researcher collected data from the clinical charts of ICD recipients who had attended ICD clinics from January 1, 2000 to May 31, 2005. The researcher examined the charts to confirm that the criteria for study inclusion were met. Once the established criteria were met, the researcher recorded the data of applicable subjects on the collection sheet (Appendix E).

\section{Data Analysis}

This study utilized descriptive statistics, correlations, and regression models to perform the required statistical analyses. Calculations were performed by using SPSS 13 for Windows (SPSS, Inc., 2005).

For the purposes of this study, appropriate shock was defined as a shock developing in the presence of VT or VF, and inappropriate shock therapy (IST) was defined as a shock developing in the absence of VT or VF. For data analysis purposes, the occurrence of inappropriate shock therapy was considered as the dependent variable. Independent variables included sex, age, NYHA Functional Class, LVEF, structural / nonstructural heart disease, and AF/atrial tachycardia. 
two groups: ages $<65$, and ages $\geq 65$. The convention within medical literature is to present LVEF by range. Thus, the researcher utilized the three levels of classification of LVEF ranges utilized in the literature: normal $\geq 50 \%$, moderately depressed: $35-49 \%$, severely depressed $\leq 34 \%$. Therefore, in this analysis, ordinal variables (e.g., NYHA functional class, LVEF) and age group were used in chisquare procedures to test the frequencies of categorical variables related to IST.

The following statistical analyses were performed to achieve the specific aims of this study. Continuous data, such as age and follow-up months, were expressed as a mean and standard deviation $(\mathrm{M} \pm \mathrm{SD})$. Categorical data were compared utilizing a chi-square test. Predictors of risk factors were determined by multivariate logistic regression analysis. The alpha level for this study was established at $5 \%(p=.05)$. Correspondingly, when the probability of making an alpha error was equal to or less than $5 \%(\mathrm{p} \leq 0.05)$, the result was considered as statistically significant.

To achieve Specific Aim \#1 (to describe the incidence of appropriate and inappropriate shock occurring in a group of ICD recipients seen at the specified university medical facility between January 2000 and May 2005 for emergent and routine follow-up visits), variables were analyzed and the following descriptive statistics were performed. 
Calculation of the following factors required special attention: the total number of appropriate shock occurrence(s) and the total number of inappropriate shock occurrence(s); and the percentage of appropriate shock and inappropriate shocks per total number of patients. These rates of appropriate and inappropriate ICD shock therapies were determined by dividing the number of therapies experienced by the total number of patients, by the number and percentage of men and women experiencing inappropriate shocks.

To achieve Specific Aim \#2 (to describe the relative risk between IST and specific factors i.e., age, gender, heart disease severity, structural heart disease, nonstructural heart disease, atrial fibrillation) the following steps were taken:

1) The frequency and proportion of each clinical risk factor associated with an IST was first calculated.

2) The researcher then analyzed the relationships between each risk factor and the frequency of ISTs, using chi square testing. Following that, the researcher applied a logistic regression model to identify the clinical predictor(s).

Post hoc testing was employed to detect significant differences among the causes of an IST. If no significant differences were detected, the next step was to use another procedure to further investigate any relationships between the frequency of inappropriate shock therapy and certain variables and/or risk factors by adding a covariate in the event that another variable was confounding the results. 
IST in patients with ICDs 53

To achieve Specific Aim \#3 (to describe the frequency of ISTs in a group of ICD recipients by risk factors (e.g., atrial fibrillation, lead problems, double counting) and the frequency and proportion of each risk factor associated with an IST, the following procedures were utilized. The number of ISTs for each risk factor (i.e., the presence of atrial fibrillation, lead problems, double counting) was divided by the number of IST events experienced per patient, and by the total number of patients over time.

To achieve Specific Aim \#4 (to investigate any significant correlations between relevant clinical factors and the occurrence of IST), an analysis examined the relative risks between structural heart disease, non-structural heart disease, heart disease severity and the incidence of an IST. The clinical factors examined included antiarrhythmic medications taken, device mode, model, and device programming at the time of the inappropriate shock event.

\section{Human Subjects}

This study was a retrospective chart review with limited access to identifying personal information. Therefore, with the authorization of an HIPPA Waiver (i.e., waiver of consent), in accordance with the HIPPA Privacy Rule, 45 CFR 164, section 512 (I), the need for signed informed consent was waived. IRB approval was obtained from USD (Appendix E) and from UCSD Medical Center 
(Appendix F) prior to data collection. The direct risks to participants in the study were minimal and every effort was made to protect confidentiality. Only a code number was used to identify participants, and no patient identifiers appeared on any data collection sheet. All data were stored in a locked file cabinet at the researcher's residence and only accessible to the researcher. All data were kept for a minimum of five years before being destroyed. Results were only reported through unidentifiable or aggregated means.

\section{Risk Management}

Only the researcher had access to the anonymous subject data throughout the research process. Prior to analysis, all subjects were assigned a case number. The protected health information of each patient was not reused or disclosed for any purposes other than that of the study.

\section{Potential Benefits}

There were no immediate, specific benefits to any individual subjects. However, the potential benefits of this research to the society were significant. An enhanced understanding of the predisposing factors related to inappropriate shock can potentially assist health care professionals in providing more effective patient education and clinical interventions. In addition, such descriptive research can 
provide a basis for future research that ultimately may enhance the well being of all ICD patients.

\section{Risk/Benefit Ratio}

Thus, from the discussion above, the potential benefits of this research outweighed the minimal risks to subjects in this study. 
IST in patients with ICDs 56

\section{CHAPTER IV}

\section{RESULTS}

\section{Subjects and Sample Characteristics}

Two hundred and twelve patients were listed on the Electrophysiology laboratory's ICD roster. Out of that group, one minor patient (i.e., under 18 years old) was excluded. Also excluded were patients who came to the electrophysiology laboratory solely for ICD device implantations, generator changes, or lead replacement procedures. The researcher was unable to locate 22 charts and noted key data missing from the records of another 43 patients. The remaining 119 patients had sufficient data for analysis and review. Figure 3 illustrates the schematic summary of subject inclusion.

Using the period from January 1, 2000 to May 31, 2005, data from 119 patient records were included in this study; a total of 2,868 months were analyzed. The mean follow-up period was $24.1 \pm 16.2$ months (ranging from 1 to 53 months). Patients with 53 months of follow-up had received ICD implantations at an earlier time than in 2000 .

Subject demographic and clinical characteristics are displayed in Table 3 The researcher's chart reviews uncovered a variety of indications for ICD implantation, with many patients having more than one type of heart pathology diagnosed. In examining the patients and their characteristics, the majority of participants were male $(\mathrm{n}=98 ; 82.4 \%)$; were NYHA Functional Class II $(\mathrm{n}=39 ; 32.8 \%)$; and had experienced a severe decrease in LEVF $(\mathrm{n}=90 ; 75.6 \%)$. Only three subjects had nonstructural heart disease. With regard to age, there were slightly more patients in the elderly group (age $\geq 65, n=67$; age 
IST in patients with ICDs 57

$<65, \mathrm{n}=52)$, but this difference was not statistically significant $\left(\chi^{2}=1.891, \mathrm{p}>.05\right)$.

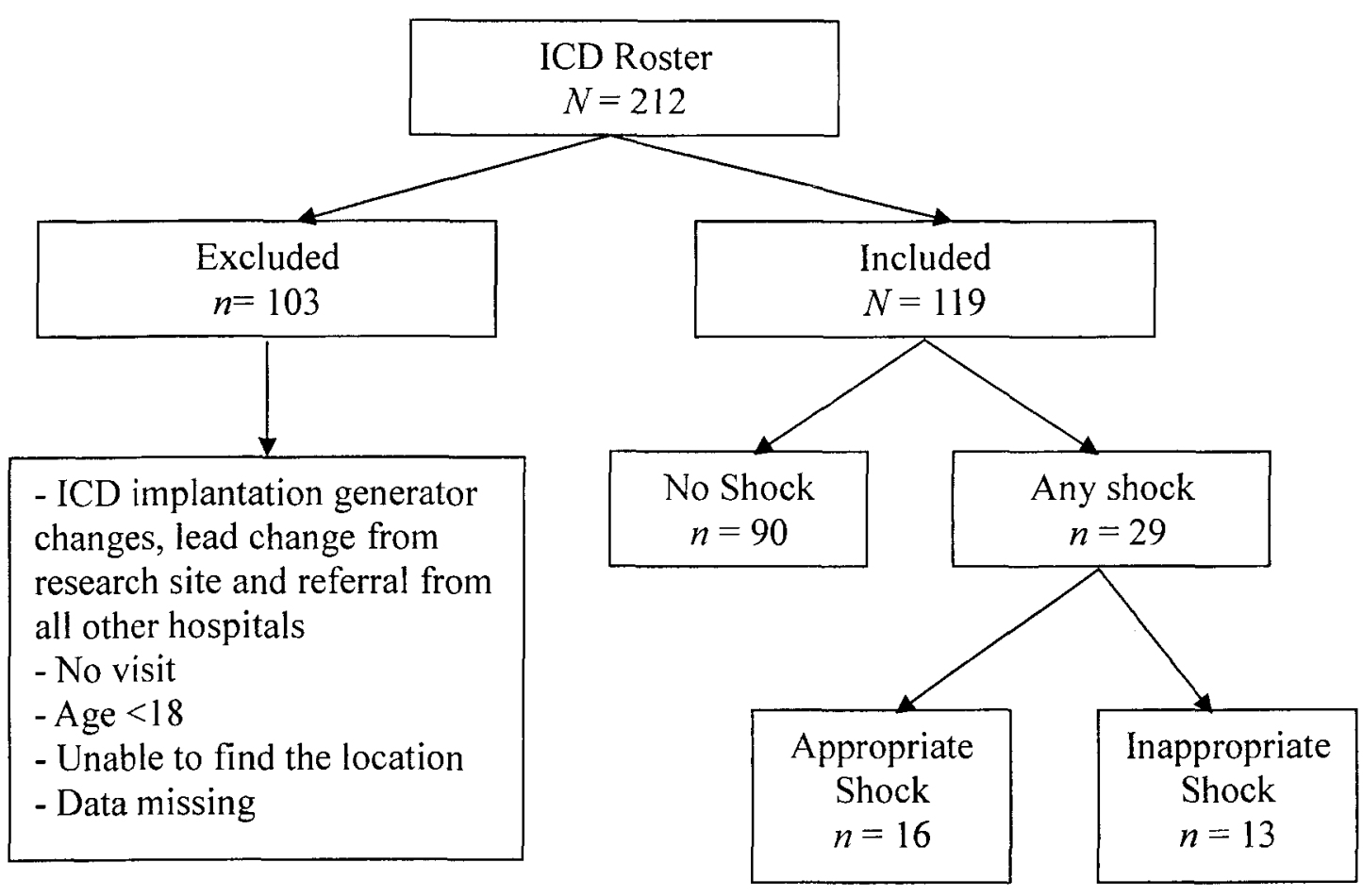

Figure 3 Schematic Summary of Subject Inclusion 
Table 3

Demographic and Clinical Characteristics of Subjects

\begin{tabular}{|c|c|}
\hline Variable & Outcome $(\%)$ \\
\hline \multicolumn{2}{|l|}{$\overline{\operatorname{Sex}}$} \\
\hline Men & $98(82.4 \%)$ \\
\hline Women & $21(17.6 \%)$ \\
\hline \multicolumn{2}{|l|}{ Age } \\
\hline Mean (in years)/Range & $65.4 \pm 15(29-89)$ \\
\hline$<65$ & $51.0 \pm 9.6$ \\
\hline$\geq 65$ & $76.6 \pm 6.4$ \\
\hline \multicolumn{2}{|l|}{ Implant Indications } \\
\hline $\mathrm{SCD}$ & $9(7.6 \%)$ \\
\hline $\mathrm{VT} / \mathrm{VF}$ & $29(24.4 \%)$ \\
\hline $\mathrm{ICM}$ & $42(35.3 \%)$ \\
\hline DCM & $35(29.3 \%)$ \\
\hline $\mathrm{HCM}$ & $2(1.7 \%)$ \\
\hline AVRD & $2(1.7 \%)$ \\
\hline \multicolumn{2}{|l|}{ Heart Disease } \\
\hline Structural & 116 \\
\hline Non Structural & 3 \\
\hline \multicolumn{2}{|l|}{ NYHA Functional Class } \\
\hline I & $27(22.7 \%)$ \\
\hline II & $52(43.7 \%)$ \\
\hline III & $39(1.0 \%)$ \\
\hline IV & $1(0.8 \%)$ \\
\hline \multicolumn{2}{|l|}{ LVEF $\mathrm{n}=118$} \\
\hline $50 \%$ & $10(8.4 \%)$ \\
\hline $35-49 \%$ & $18(15.1 \%)$ \\
\hline$<35 \%$ & $90(75.6 \%)$ \\
\hline
\end{tabular}

$\mathrm{ARVD}=$ Right Ventricular Dysplasia, $\mathrm{HCM}=$ Hypertrophy Cardiomyopathy

DCM = Dilated Cardiomyopathy, ICM = Ischemic Cardiomyopathy, SCD $=$ Sudden Cardiac Death .

$\mathrm{VT} / \mathrm{VF}=$ Ventricular Tachycardia/ Ventricular Fibrillation 
Data Analysis Related to the Aims of This Study

\section{Specific Aim \#1}

Specific aim \# 1 of the study was to describe the incidence of appropriate and inappropriate shock occurrence in a group of ICD recipients, as well as to account for the incidence of appropriate shocks and inappropriate shocks for patients who visited the medical facility between January 2000 and May 2005 for emergent and routine follow-up visits.

Descriptive statistical analysis was performed to determine the profiles of shock occurrence in this study group. In this follow-up period, with a mean time follow-up of $24.1 \pm 16.2$ months (range of $1-53$ months), there were 90 subjects who had not experienced any shock treatment. Sixty shock events occurred for $29(24.4 \%)$ patients; 16 (13.4\%) patients received 44 appropriate shocks and $13(10.9 \%)$ patients received 16 inappropriate shocks. Thirteen out of 119 patients (11\%) experienced IST, and 12 out of 13 IST subjects were men. Shock profiles are displayed below in Table 4 
Table 4

Shock Profiles

\begin{tabular}{lcc}
\hline \multicolumn{1}{c}{ Shock Type } & $\begin{array}{c}\text { Number of patients } \\
(\%) \mathrm{N}=119\end{array}$ & $\begin{array}{c}\text { Number of Shocks } \\
\text { No Shock }\end{array}$ \\
Appropriate Shock(only) & $90(75.6)$ & 0 \\
Inappropriate Shock (only) & $96(13.4)$ & 44 \\
Coexisting Shock & $4(7.6)$ & 16 \\
Appropriate Shock Total & $20(17)$ & - \\
IST total & $13(11)$ & \\
Male & $12(10)$ & \\
Female & $1(.8)$ & $60+$ \\
Shock Total & $29(24.4)$ & \\
\hline
\end{tabular}

See Table 5 for other demographic information concerning the IST patients.

Table 5

Inappropriate Shock Therapy Patients Profile

\begin{tabular}{lrrr}
\hline Variables & \multicolumn{3}{c}{ Outcome (Number of Patients) } \\
\hline Gender & Male $(12)$ & Female $(1)$ & \\
Age & $<65(6)$ & $\geq 65(7)$ & \\
NYHA Class & $\mathrm{I}(4)$ & $\mathrm{II}(2)$ & $\mathrm{III}(7)$ \\
LVEF & $>50 \%(2)$ & $35-49 \%(1)$ & $<35 \%(9)$ \\
Structural HD & Yes $=13$ & No $=0$ & \\
Hx of AF & Yes $=10$ & No $=3$ & \\
\hline
\end{tabular}

Specific Aim \#2

The second specific aim of this study was to describe four associations: the

relative risk relationships between age group and IST; gender and IST, heart disease 
severity and IST; structural/ non-structural heart disease and IST; and the history of atrial fibrillation and IST.

To test the relationship between heart disease severity and IST, the researcher examined whether the incidence of inappropriate shock correlated with ICD recipients' severity of disease according to left ventricular ejection fraction (LVEF; i.e., very severe $\leq 35 \%$, moderate severe $36-49 \%$, normal $\geq 50 \%$ ). Additionally, the NYHA functional classes (i.e., I, II, III, IV) of structural heart disease were examined to identify any significant correlations with the ICD recipients' non-structural heart disease.

Chi-square analysis was chosen to compare the IST group to the non-IST group in terms of the frequencies of ordinal variables (i.e., NYHA functional class, LVEF) and categorical variables (i.e., structural heart disease and non structural heart disease) as related to an inappropriate shock. These findings are displayed in Table 6 
Table 6

Inappropriate Shock in Chi-Square Com6parisons between IST and Non-IST patients $(\mathrm{N}=119)$

\begin{tabular}{|c|c|c|c|c|}
\hline \multirow{2}{*}{$\begin{array}{l}\text { Potential Clinical Predictors } \\
\qquad(\mathrm{N})\end{array}$} & \multicolumn{2}{|c|}{ IST } & \multirow[t]{2}{*}{$\chi^{2}$} & \multirow[t]{2}{*}{$\mathrm{p}$} \\
\hline & Yes & No & & \\
\hline 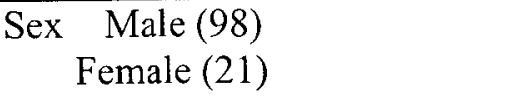 & $\begin{array}{c}12 \\
1\end{array}$ & $\begin{array}{l}86 \\
20\end{array}$ & 1.242 & .537 \\
\hline $\begin{array}{c}\text { Age Group }<65 \text { (52) } \\
\geq 65(63)\end{array}$ & $\begin{array}{l}6 \\
7 \\
\end{array}$ & $\begin{array}{l}46 \\
59\end{array}$ & .809 & .667 \\
\hline $\begin{aligned} & \text { NYHA Class } \text { I } \\
& \text { II } \\
& \text { III } \\
& \text { IV } \\
&\end{aligned}$ & $\begin{array}{l}4 \\
2 \\
7 \\
0\end{array}$ & $\begin{array}{c}22 \\
50 \\
32 \\
1 \\
\end{array}$ & 8.731 & .189 \\
\hline $\begin{array}{ll}\text { LVEF } & >50 \% \\
& 35-49 \% \\
& <34 \% \\
\end{array}$ & $\begin{array}{l}2 \\
1 \\
9\end{array}$ & $\begin{array}{c}8 \\
17 \\
80\end{array}$ & 1.792 & .774 \\
\hline $\begin{aligned} \text { Structural HD } & \text { Yes (115) } \\
& \text { No (4) }\end{aligned}$ & $\begin{array}{c}13 \\
0\end{array}$ & $\begin{array}{c}102 \\
4 \\
\end{array}$ & .410 & 815 \\
\hline $\begin{array}{r}\text { Atrial Fibrillation Yes (13) } \\
\text { No (10) }\end{array}$ & $\begin{array}{c}10 \\
3\end{array}$ & $\begin{array}{c}3 \\
70\end{array}$ & 11.993 & $.002 *$ \\
\hline
\end{tabular}

$\mathrm{df}=2,{ }^{*} \mathrm{p}<.01$

To characterize patients who were prone to develop an inappropriate shock, the

researcher did the following: 1) comparison of clinical variables; 2) analysis of

characteristics, including demographic information; 3) examination of subjects' histories

of atrial arrhythmia, underlying heart disease, and ejection fraction; and 4) examination

of the clinical characteristics of each qualifying arrhythmia. None of these variables was

predictive of a future development of IST, except atrial tachycardia arrhythmia. To 
account for the difference in the relationship between these potential risk factors,

regression models were used; however, no predictive variables were identified. Details of the comparison of variables between the IST and non-IST groups are summarized in

Table 7.

Table 7

Likelihood Ratio Tests

Model Fitting Likelihood Ratio Tests

Criteria

Criteria

$-2 \log$

Likeliness of

Chi-Square

df

$\mathrm{p}$

Reduced Model

Intercept

37.080

.000

0

Age Group

38.487

1.407

2

.495

Gender

38.489

1.409

2

.494

NYHA Class

47.543

10.463

6

.106

LVEF

38.146

1.066

4

.900

Structural

37.187

.107

2

.948

AF / Atachy

51.959

14.879

2

$.001 *$

$*_{p}=.001$.

As depicted in Table 6, atrial fibrillation was significantly correlated with the incidence of IST $\left(\chi^{2}=11.993, p=.002\right)$. However, gender $\left(\chi^{2}=1.242, p=5.37\right)$, age $\left(\chi^{2}\right.$ $=.809, \mathrm{p}=.667)$, NYHA $\left(\chi^{2}=8.731, \mathrm{p}=.189\right), \operatorname{LVEF}\left(\chi^{2}=1.792, \mathrm{p}=.774\right)$, and structural 
heart disease $\left(\chi^{2}=.410, \mathrm{p}=.815\right)$ were not statistically significant identifiers for IST.

These same variables were repeated using a logistic regression analysis, and results were similar. In this analysis, atrial tachyarrhythmia demonstrated an even higher significance in the regression analysis $\left(\chi^{2}=14.879, \mathrm{p}=.001\right)$ than in the chi square analysis $(\mathrm{p}=.002)$.

Specific Aim \#3

This study's third specific aim was to describe the frequency of ISTs in a group of ICD recipients by risk factors (e.g., atrial fibrillation, lead problems, double counting). Thus, descriptive statistics evaluating the frequency and proportion of each risk factor associated with an IST were performed.

The number of ISTs for each independent variable (e.g., atrial fibrillation, double counting) is reported and divided by the number of inappropriate shock therapies experienced per patient and by the total number of patients over time.

IST's occurred in eight patients in the presence of atria arrhythmias (i.e., flutter, fibrillation) or sinus tachycardia. In one subject, an IST occurred following a missed dose of mexiletine. Other concurrent clinical events included double counting and T-wave over-sensing secondary to an imbalance of electrolytes. Table 8 displays the incidence of 
IST by variable factors.

Table 8

Incidence of ISTs by Variable Factors

\begin{tabular}{|l|l|l|l|l|l|l|}
\hline & $\begin{array}{l}\mathrm{AF} / \\
\text { A tachy }\end{array}$ & $\begin{array}{l}\text { ST } \\
\text { NSR }\end{array}$ & $\begin{array}{l}\text { Double } \\
\text { counting }\end{array}$ & $\begin{array}{l}\text { Lead } \\
\text { problem }\end{array}$ & $\begin{array}{l}\text { Drug } \\
\text { Interaction }\end{array}$ & Total \\
\hline $\begin{array}{l}\text { Number of } \\
\text { subjects }\end{array}$ & 8 & 2 & 2 & 1 & 1 & 13 \\
\hline $\begin{array}{l}\text { Number of } \\
\text { IST }\end{array}$ & 10 & 2 & 2 & 1 & 1 & 16 \\
\hline
\end{tabular}

$\mathrm{NSR}=$ normal sinus rhythm, $\mathrm{ST}=$ sinus tachycardia

Specific Aim \#4

The study's fourth specific aim was to investigate significant correlations between

clinical information and an IST, and, taken in combination, to reveal any clinical predictability for the incidence of an IST. Variables analyzed include demographic characteristics, histories of previous underlying heart disease, ejection fraction, and medications taken at the time of the IST.

Medical charts and ICD follow-up records were reviewed for the clinical characteristics of the presenting arrhythmia. All information regarding episodes of stored arrhythmias were recorded at the discretion of the physician treating the individual patient. The elements recorded in the subject record as possible predisposing factors triggering ISTs are discussed below. 
IST in patients with ICDs 66

Most patients at risk for an IST had severe chronic heart disease and multiple independent risk factors for atrial fibrillation. More than $70 \%$ of the ICD patients had significant coronary artery disease, and most had severe left ventricular dysfunction with an ejection fraction of less than $30 \%$. A minority of ICD patients $(n=3)$ had normal coronary arteries and electrically compromised, right ventricular dysplasia, mitral valve prolapse, or hypertrophic cardiomyopathy (HCM). Most ICD patients were also at risk for potential triggers of inappropriate shock known to precipitate atrial fibrillation and lead to SCD if left unchecked. These triggers included hyperthyroidism, diabetes mellitus, and valvular heart disease. 
Table 9

Characteristics of Subjects and Incidence of Inappropriate Shock Therapy

\begin{tabular}{|c|c|c|c|c|c|c|c|c|c|c|}
\hline $\begin{array}{l}P \\
t \\
\#\end{array}$ & $\begin{array}{l}\text { Age } \\
\text { Sex }\end{array}$ & $\begin{array}{l}\text { Implant } \\
\text { Indica-tion }\end{array}$ & $\begin{array}{c}\text { History } \\
\text { of } \\
\text { HD }\end{array}$ & $\begin{array}{l}\mathrm{N} \\
\mathrm{Y} \\
\mathrm{H} \\
\mathrm{A}\end{array}$ & $\begin{array}{l}\mathrm{E} \\
\mathrm{F}\end{array}$ & $\begin{array}{c}\text { Cause of IST } \\
\text { Event }\end{array}$ & Mode & $\begin{array}{c}\text { AA Drug } \\
\text { at time of } \\
\text { Event }\end{array}$ & $\begin{array}{l}\text { F- } \\
\text { up } \\
(\mathrm{M})\end{array}$ & Intervention \\
\hline 1 & $\begin{array}{l}82 \\
M\end{array}$ & VT CHF & $\begin{array}{l}\text { Chr AF CABG } \\
\text { Syncope } \\
\text { Hypothyroidism }\end{array}$ & II & 35 & $\begin{array}{l}\text { One shock due to AF } \\
\text { Charge time } 6.55 \mathrm{sec} \text {. }\end{array}$ & VVIR & $\begin{array}{l}\text { Metoprolol } \\
\text { Lanoxin }\end{array}$ & 49 & $\begin{array}{l}\text { Up grade to } \\
\text { dual chamber } \\
\text { ICD }\end{array}$ \\
\hline 2 & $\begin{array}{l}68 \\
M\end{array}$ & VT ICM & $\begin{array}{l}\text { NSVT } \\
\text { PAF }\end{array}$ & I & 58 & $\begin{array}{l}\text { Missing one dose of } \\
\text { Mexiletine }\end{array}$ & DDD & $\begin{array}{l}\text { Coreg Digoxin } \\
\text { Amidarone }\end{array}$ & 25 & Monitor VT \\
\hline 3 & $\begin{array}{l}48 \\
M\end{array}$ & DCM & $\begin{array}{l}\text { NIDCM } \\
\text { HTN ESRD }\end{array}$ & III & 10 & Lead dislodge & $\begin{array}{l}\text { Biv } \\
\text { DDD }\end{array}$ & Coreg Laoxin & 18 & $\begin{array}{l}\text { Reposition } \\
\text { lead }\end{array}$ \\
\hline 4 & $\begin{array}{l}85 \\
M\end{array}$ & VT & MVP & I & N/A & Discharge for AF & VVI & Coreg Digoxin & 53 & $\ldots$ \\
\hline 5 & $\begin{array}{l}87 \\
M\end{array}$ & $\mathrm{DCM}$ & PAF & III & 15 & Double counting & $\begin{array}{c}\text { Biv } \\
\text { DDD }\end{array}$ & Digoxin & 10 & Expired \\
\hline
\end{tabular}




\begin{tabular}{|c|c|c|c|c|c|c|c|c|c|c|}
\hline $\begin{array}{l}\mathrm{Pt} \\
\#\end{array}$ & $\begin{array}{c}\mathrm{Ag} \\
\mathrm{e} \\
\operatorname{Sex}\end{array}$ & $\begin{array}{l}\text { Implant } \\
\text { Indication }\end{array}$ & $\begin{array}{l}\text { History } \\
\text { of } \\
\text { HD }\end{array}$ & $\begin{array}{l}\mathrm{N} \\
\mathrm{Y} \\
\mathrm{H} \\
\mathrm{A}\end{array}$ & $\begin{array}{l}\mathrm{E} \\
\mathrm{F}\end{array}$ & $\begin{array}{c}\text { Cause of IST Shock } \\
\text { Event }\end{array}$ & Mode & $\begin{array}{c}\text { AA Drug at time } \\
\text { of Event }\end{array}$ & $\begin{array}{l}\text { F- } \\
\text { Up } \\
(\mathrm{M})\end{array}$ & Intervention \\
\hline 6 & $\begin{array}{l}44 \\
M\end{array}$ & $\mathrm{DCM}$ & $\begin{array}{l}\text { CHF } \\
\text { MI } \\
\text { LBBB }\end{array}$ & III & 24 & Sinus tachycardia as VT & $\begin{array}{l}\text { Biv } \\
\text { DDD }\end{array}$ & Coreg Digoxin & 7 & $\begin{array}{l}\text { VT zone } \\
\text { increased, VT } \\
\text { onset, stab } \\
\text { discrimination } \\
\text { ON }\end{array}$ \\
\hline 7 & $\begin{array}{l}48 \\
\mathrm{M}\end{array}$ & $\mathrm{HCM}$ & AF RVR & II & 34 & One shock for AF & DDDR & $\ldots$ & 46 & $\widetilde{ }$ \\
\hline 8 & $\begin{array}{l}71 \\
M\end{array}$ & DCM & $\begin{array}{l}\mathrm{CHF} \\
\mathrm{AF}\end{array}$ & I & 18 & $\begin{array}{l}\text { One shock } \\
\text { for atrial flutter }\end{array}$ & DDDR & $\begin{array}{l}\text { Mexiletine } \\
\text { Sotalol Lanoxin }\end{array}$ & 22 & $\begin{array}{l}\text { Arrange DFT } \\
\text { testing }\end{array}$ \\
\hline 9 & $\begin{array}{l}74 \\
M\end{array}$ & VT & $\mathrm{ICM}$ & I & 35 & $\begin{array}{l}\text { Shock for SVT and AF } \\
\text { RVR } \\
\text { Dehydration, Creatine } \uparrow \\
\mathrm{K}^{+} \uparrow\end{array}$ & DDDR & $\begin{array}{l}\text { Sotalol } \\
\text { Laoxin } \\
\text { Amidarone } \\
\text { Coreg }\end{array}$ & 41 & $\begin{array}{l}\text { Coreg increase } \\
\text { to } 625 \mathrm{mg} \text {. DFT } \\
\text { remained stable } \\
\text { on amidarone } \\
\text { w/no } \\
\text { antiarrthmic } \\
\text { event. }\end{array}$ \\
\hline
\end{tabular}




\begin{tabular}{|c|c|c|c|c|c|c|c|c|c|c|}
\hline $\begin{array}{l}\mathrm{Pt} \\
\#\end{array}$ & $\begin{array}{l}\mathrm{Ag} \\
\mathrm{e} \\
\mathrm{Sex}\end{array}$ & $\begin{array}{l}\text { Implant } \\
\text { Indication }\end{array}$ & $\begin{array}{l}\text { History } \\
\text { of } \\
\text { HD }\end{array}$ & $\begin{array}{l}\mathrm{N} \\
\mathrm{Y} \\
\mathrm{H} \\
\mathrm{A}\end{array}$ & $\begin{array}{l}E \\
F\end{array}$ & $\begin{array}{c}\text { Cause of IST Shock } \\
\text { Event }\end{array}$ & Mode & $\begin{array}{c}\text { AA Drug at time } \\
\text { of Event }\end{array}$ & $\begin{array}{l}\text { F- } \\
\text { Up } \\
(\mathrm{M})\end{array}$ & Intervention \\
\hline 10 & $\begin{array}{l}49 \\
M\end{array}$ & VT & TOF VHD & III & 30 & $\begin{array}{l}\text { One shock for A Tachy } \\
\text { secondary induced by } \\
\text { exercise }\end{array}$ & DDDR & Coreg & 10 & $\begin{array}{l}\text { Since ICD firing } \\
\text { in VT zone } \\
\text { during exercise } \\
\text { induced ST. } \\
\text { After VT turned } \\
\text { off. VT } \\
\text { Ablation }\end{array}$ \\
\hline 11 & $\begin{array}{l}79 \\
F\end{array}$ & AVRD & $\begin{array}{l}\text { NSVT SMVT } \\
\text { PAF }\end{array}$ & $\mathrm{I}$ & 72 & $\begin{array}{l}\text { Two shocks for sinus } \\
\text { tachycardia }\end{array}$ & $\begin{array}{l}\text { Biv } \\
\text { DDD }\end{array}$ & $\begin{array}{l}\text { Cozaar } \\
\text { Amiodarine } \\
\text { Norvasc }\end{array}$ & 53 & $\begin{array}{l}\text { No evidence for } \\
\text { reversible } \\
\text { perfusion to } \\
\text { suggest } \\
\text { inducible } \\
\text { coronary } \\
\text { insufficiency }\end{array}$ \\
\hline 12 & $\begin{array}{l}54 \\
M\end{array}$ & $\begin{array}{l}\text { ICM } \\
\text { NIDCM }\end{array}$ & Chr. AF & II & 30 & $\begin{array}{l}\text { One shock due to double } \\
\text { counting }\end{array}$ & $\begin{array}{l}\text { Biv } \\
\text { DDD }\end{array}$ & $\begin{array}{l}\text { Coreg } \\
\text { Digoxin }\end{array}$ & 18 & $\begin{array}{l}\text { Rate increase to } \\
175 \text {, VT interval } \\
\text { decrease to } 343 \\
\text { ms }\end{array}$ \\
\hline 13 & $\begin{array}{l}48 \\
M\end{array}$ & NICM & Chr AF & III & 22 & $\begin{array}{l}4 \text { shocks - } 3 \text { for VT VF } \\
1 \text { for AF RVR while } \\
\text { performing stress test }\end{array}$ & $\begin{array}{l}\text { Biv } \\
\text { DDD }\end{array}$ & $\begin{array}{l}\text { Coreg, Cozaar } \\
\text { Digoxin }\end{array}$ & 22 & $\begin{array}{l}\text { ICD normal } \\
\text { function } \\
\text { Recommend } \\
\text { rate control }\end{array}$ \\
\hline
\end{tabular}


IST in Patients with ICDs 70

\section{Description of 13 IST Patients}

As presented in Table 9, in the IST group, all patients had structural heart disease. Twelve patients were men. Subjects aged 65 years and older were slightly more numerous than younger patients (7 vs. 6), but this difference was not statistically significant. Eleven out of 13 patients had LVEFs that were severely depressed (i.e., below $35 \%$ ), but there were no patients experiencing IST that had moderately depressed LVEFs. Two patients had a normal LVEF: 1) a patient with an LVEF of $58 \%$ who had CAD NSVT; 2) another patient with an LVEF of $72 \%$ who had poor right ventricular function due to right ventricular dysplasia.

The major causative factor of IST in this group was atrial fibrillation $(n=8)$. Two patients had sinus tachycardia. Double counting occurred in two patients, one patient's IST was associated with lead dislodgement, and another patient's IST was caused by missing one dose of Mexiletine. This type of event has been posited to be associated with an increased defibrillation threshold (DFT) (Murakawa, Yamshita, Kanese, Omota, 1998; Rajawat, Patel, Gerstenfeld, Nayak, and Marchinski, 2004).

Regardless of a variety of indications and disease diagnoses (including two patients with congenital heart disease), 10 out of 13 subjects who experienced IST had coexisting chronic AF or paroxysmal atrial fibrillation (PAF). Finally, three patients had no history of chronic AF; however, they all had at least one inherited risk factor for developing AF.

Another finding from this group was the importance of occurrences of trigger events. In two patients (Patient 1 and Patient 4) the ICD device was suspected to lack the ability to discriminate between SVT and VT, and, after changing VVI mode to DDD, 
there was no further IST. However, IST occurred in the remaining patients who were implanted with a dual chamber device (Patient 5) and a biventricular device (Patient 6 and Patient 8). According to chart records, a missed Mexiletine dose was suspected to be the trigger of the IST secondary to alternating defibrillation threshold for Patient 2.

Two subjects receiving ISTs had similar situations. Patient 10, who had atrial tachycardia, received an IST while he was performing extreme exercise, and Patient 13 received an IST while he was undergoing a stress test. The patient activity at the time of the lead dislodgement case (Patient 3) was not recorded. However, all of these three patients were males and in their 40s.

\section{Summary}

The major finding of this study was a significant correlation between the occurrence of atrial fibrillation and the incidence of IST. The trigger events precipitating IST were varied in this study population, and their salience as clinical predictors of IST are discussed in the next chapter. 


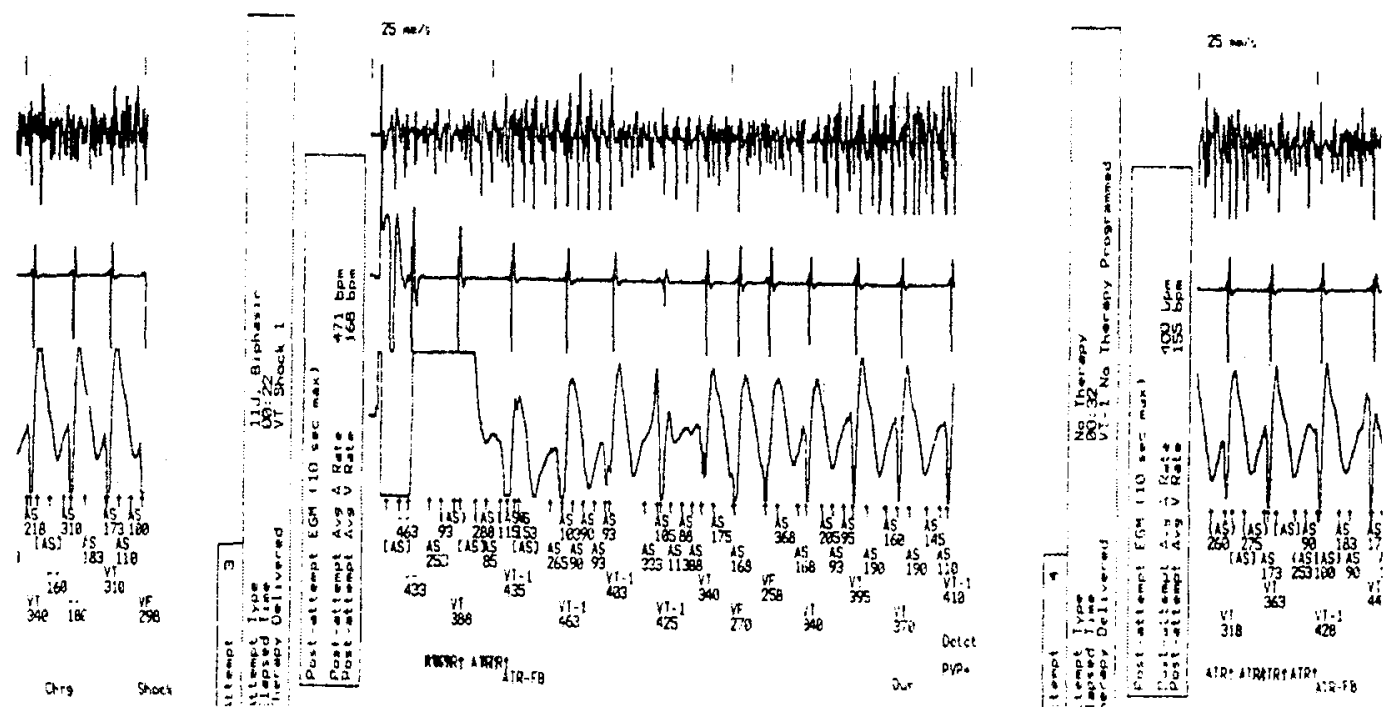

Figure 3

Patient 10 received an IST while he was performing ext:eme exercise.

An inappropriate shock from atrial fibrillation with rapid ventricular response.
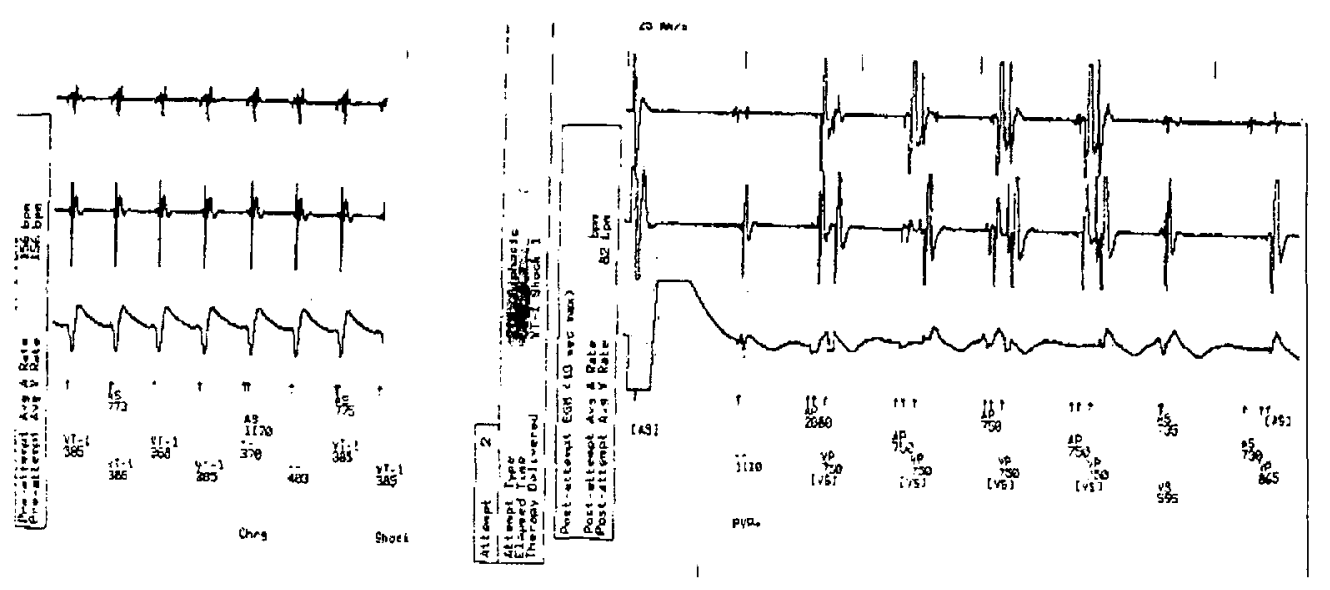

Figure 4

Patient 13 received an IST while he was undergoing a stress test.

Inappropriate shock from a sinus tachycardia that had a ventricular rate fast enough to be detected in the VT zone of the device 


\section{CHAPTER V \\ DISCUSSION}

\section{Overview}

This investigation is an updated cohort study of inappropriate shock therapy. The study represents the first research findings from a nursing perspective on the physiological aspects of IST in ICD recipients. Unlike previous cohort studies that only present the rates of causes of IST, including the most recent such study by Thenus et al. (2005), this study explores underlying trigger events by incorporating these events at the time when IST occurred, as well as by correlating subjects' clinical histories.

The actual data collection period of Thenus et al.'s (2005) study is not indicated; but the observation period of this present study was specifically conducted at a teaching hospital as well as a tertiary referral hospital in Southern California from July 2000 to May 2005, with a mean follow-up period of $24.1 \pm 16.2$ months.

Overall, this study reveals that, in $13(9 \%)$ out of 119 patients who received inappropriate shock, AF remained the major cause of IST. In addition, 12 out of 13 patients receiving ISTs were men. The researcher posits that ISTs may be related to men's increased risk for atrial fibrillation. However, given that 98 out 119 patients (82.4\%) were men, this conclusion is based on a small sample size that failed to achieve statistical significance and must be viewed with caution $(\chi 2=0.995, \mathrm{p}>.05)$. 


\section{Incidence Rates}

In previous cohort studies, incidence rates of $22 \%$ (Grimm et al., 1993) and 14\% (Rinaddi et al., 2004: Thenus et al., 2005) were documented, and inappropriate ICD therapy was attributed to atrial tachyarrhythmias. However, it is unknown what percentage of total events atrial tachyarrhythmias constituted in Thenus et al.'s study. The incidence of ISTs in this present study was $11 \%$. This lower incidence might be due to the following reasons: (a) continuous refinement in the ICD devices; (b) rigorous procedures for performing a follow-up visit. The incidence rate also may have been underestimated because of patients lost to follow-up (e.g., moving, traveling, inability to locate patient or chart). However, those events also occur in most retrospective cohort studies.

\section{Age and Gender}

As in previous studies (Grimm et al.1993; Nanthakumar, 2003; Rinaddi, 2004; Thenus et al., 2005), the present study did not show any significant difference in age and gender between the IST group and the non-IST group. Even though 12 out of the 13 IST subjects were men, the large proportion of men receiving this form of treatment was not significantly different between the groups $(p=.537)$.

\section{Atrial Fibrillation}

Previous studies have investigated whether clinical variables could predict the delivery of IST in ICD recipients. Rinaddi et al. (2004) and Nanthakumar et al. (2003) observed previous histories of $\mathrm{AF}$ at the time of implantation to predict the incidence of inappropriate shock for patients with single chamber ICDs. Since the first cohort study (Grimm et al., 1993), and despite the advent of DDD, AF still remains the major cause of 
IST (Thenus et al., 2005).

\section{NYHA Functional Class}

Nanthakumar et al. (2003) also noted that NYHA Class I could predict IST. In this study, however, the subjects' statuses of function classes fluctuated and could not reflect the level of severity for heart disease. Therefore, it was not surprising that identification of significance was not achieved at the level of NYHA Functional Class.

\section{Ejection Fraction}

As in the work of Thenus et al. (2005) and the present study did not found any significant differences in this factor related to the development of IST. One explanation could be that, although the value of LVEF is more objective (e.g., measured by rest technetium-99m-methoxy-isobutyl-isonitril (MIBI), echocardiography, or by the guideline of indications in Gate Bayesian Reconstruction In Emission Tomography [SPECT]), most patients were amalgamated into the severely depressed LVEF category in order to receive ICD therapy.

Eleven out of 13 patients with at least one IST experience had severely depressed LVEFs. However, other subjects with severely depressed LVEF had experienced no IST event. Therefore, the data could not support this variable as a clinical predictor.

\section{Structural Heart Disease}

A previous study (Rinaddi et al., 2004) posited that, while DCM patients comprised $50 \%$ of the study participants, a higher incidence of IST ( $80 \%)$ occurred in these patients. Rinaddi et al. concluded that patients with DCM were more likely to be at increased risk for ISTs. In this study with expanded indications, a variety of diagnoses are shown to have been occurring in ICD recipients. Because most patients had multiple 
forms of heart diseases as well as other disease processes, DCM could not be considered as an independent variable, or as a clinical predictor. However, after grouping heart disease into structural and non-structural categories, the results demonstrated that almost all ICD recipients had structural heart disease $(n=116)$. Therefore, the number of patients with non-structural heart disease $(n=3)$ was too small to utilize structural heart disease as a grouping variable to test for statistical significance.

\section{Lead Problems}

Lead problems are the second major cause of ISTs, as reported in many articles (Dorwarth, et al, 2003; Goyal, et al, 2004; Picket et al, 2004). In the present study, only one patient had an IST related to lead dislodgement. While another patient did have a lead fracture; however the lead was replaced in a timely fashion by rigorous integration, which contributed to be the lowered occurrence rate IST, as the researcher noted in the ICD record.

\section{Double Counting}

In this study, IST caused by double counting occurred in two cases in an early observation with the first generation of BiV ICD. Although dedicated BiV ICDs are now available with tachycardia detection only occurring through a single (RV) channel, continued follow-up of the many patients who received first-generation devices is needed.

\section{Drug Interaction}

In the present study, a unique finding not found in previous cohort studies was that an IST can be caused by missing one dose of Mexitil (i.e., mexiletine). In this patient, population, mexiletine function in a fashion similar to lidocaine to reduce the development of ventricular tachycardia, as has been used in hybrid therapy of ICD 
recipients (Rajawat, Patel, Gerstenfeld, Nayak, \& Marchinski, 2004). However, animal studies had reported that treatment with mexiletine increases the defibrillation threshold. Thus, suddenly missing one dose led to altering the serum level of mexiletine, which then lead to an IST (Bride et al, 1997). As a result, the association of missing one does of Mexitil and IST, is suspected.

\section{Electrolyte Imbalance}

Another IST event occurred when a patient was hospitalization for VT/VF. Predisposed dehydration increased the serum level of creatine and potassium, as the interrogation revealed VT and AF with rapid ventricular response.

Events Occurring at the Time of Inappropriate Shock Therapy Episodes

In this study, eight patients' IST were found to be AF/atrial tachycardia or SVT. In one case, there was no recorded trigger event; and in another case, the patient's single chamber ICD was replaced by a dual chamber ICD to solve the problem. Another patient was asked to increase the dosage of antiarrhythmics. Yet another patient was asked to take anti-thyroid. Adjustment of the defibrillation threshold and ablation were performed for two different patients to solve the IST problem. For the remaining two patients in the IST group, one IST occurred at the time when the patient was undergoing a testing procedure, the other IST occurred at the time when the patient was performing extreme exercise. Therefore, the clinical characteristics of patients prone to IST should be incorporated into intervention plans. 


\section{Clinical Implications}

Because ICDs are a lifesaving device, the unexpected failure of one can be catastrophic. Thus, the findings from this study may have clinical implications that relate to the safety of ICD recipients. The following are this researcher's suggestions:

1. Early identification of the etiology of unnecessary shocks to allow for the immediate institution of therapy to reduce the risk for subsequent events;

2. Careful monitoring of concomitant anti-arrhythmic drug (AAD) therapy in patients with ICD;

3. Reinforcement of the need for careful electrode lead and generator placement to reduce IST events;

4. Increased awareness that certain testing procedures (e.g., stress tests) may predispose the patient to IST;

5. Development of an updated and effective education program for nurses caring for ICD patients that incorporates current research findings regarding assessment for risk factors for IST and patient/family education regarding these factors.

Ultimately, the goal is to ensure that ICD recipients achieve optimal care and recovery status.

\section{Limitations}

This study has several limitations. One major limitation is that it is based on a retrospective design. Data were collected through chart reviews and ICD records. Some of the information that the researcher needed was difficult to obtain. For example, if a patient expired at another hospital, the cause of death was unknown and the researcher could not know if any relationship existed between the cause of death and ICD device. 
Other patient records may have been lost or were taken elsewhere (e.g., a patient might move out of the area). In addition, without the ability to contact patients, the researcher was unable to know where missing charts were located or about the existence of charts in other facilities.

This preset study data did not address the role of the programming in the genesis of IST as different programming modalities can influence the effectiveness of shock therapy. In addition, the researcher was not able to record all medications taken by the ICD recipients, and medications can alter ICD therapy. Further, the researcher was unable to obtain all ICD records for review, especially in the event of an IST occurring outside of the study site. For these reasons, the researcher may not be in a position to clearly assess the effects of risk factors and can only note inappropriate therapy prevalence based on the ICD records.

The major limitation of this study is its related small number of subjects limited to a single-center ICD clinic registry. As such, the conclusions could be buttressed by using larger multi-center registries or prospective data from future ICD research. Especially important would be focusing on data issues and avoid any potential bias resulting from incomplete data. At the outset, this researcher considered IST as the most clinically relevant event. Inappropriate anti-tachycardia therapy (ATP) that resulted in no shock or appropriate shock therapy was not assessed. Reasons for not including ATP were primarily due to missing data secondary to the ICD's memory limitations, incomplete interrogation, or cleared memory. Inclusion of any of these data could provide a fuller understanding of IST phenomenon. 
Suggestion for Future Research

Despite the technological evolution of ICD devices, AF/atrial

tachycardarrhythmia remains the major cause of IST. Efforts in future research should include investigations into the events arising from $\mathrm{AF} /$ atrial tachycardarrhythmia and clinical histories that could predispose patients to AF/atrial tachycardarrhythmia. Thus, the responses of ICD patients to triggered heart-rate exercise should be carefully studied. Since antiarhythmics have become an integral part of hybrid therapy, the alteration of the defibrillation threshold by these medications also should be a focus of future research. As an IST can be triggered by an electrolyte imbalance, there is a need to investigate the pathways by which an imbalance in specific electrolytes (e.g., potassium) are promoting the occurrence of IST. Because of the serious consequences of device malfunction (e.g., sudden death), providing a patient alert system, surveying the reasons for patients missing a follow-up appointment, and developing a the strategy to assist ICD recipients to continue regular follow - up should be encouraged. The early detection of device malfunction and immediate replacement could avert a tragedy from occurring.

In addition, little is known regarding undersensing as a contributing factor to IST, and future research should focus on this area. Although inappropriate antitachycardia pacing may not be as serious as an IST, the wrong detection information can significantly alter hemodynamic functioning. Future research studies that explore more fully all inappropriate discharges may be made possible as increased memory electrogram storage in the ICD expands.

Despite expanded indications for the use of the ICD, the percentage of women receiving ICD therapy has not increased. This continuing persistent gender differential in 
ICD therapy may need to be investigated using qualitative and quantitative methods, as a complex set of physiological and contextual factors may be operant.

This study represents an initial step in the growing body of knowledge regarding an expanding patient population. In the future, a multisite expanded longitudinal study will be necessary to confirm the results seen in this study and more clearly elucidate the multi-factorial nature of inappropriate shock therapy. 
IST in patients with ICDs 82

\section{References}

Adgey, A. A. J., Spence, M. S., \& Walsh, S. J. (2005). Theory and practice of defibrillation (2) Defibrillation for ventricular fibrillation. Heart, 91, 118-125.

Al-Ahmad, A., Wang, F. J., Homoud, M. K., Estes, N. A., \& Link, M. S.(2004). Frequent ICD shocks due to double sensing in patients with bi-ventricular implantable cardioverter defibrillators, Journal of International Cardiovascular Electrophysiology, 9, 377-381.

Alexander, A., Wayne, R, \& O'Rourke R. B. (Eds.) (2004). Hurst's: The heart (11 ${ }^{\text {th }}$ ed) New York: McGraw-Hill.

American Heart Association (2005). Heart disease and stroke statistics: 2005 update. Dallas, TX: Author. Available at http: //www.mericanheart.org/downloadable/heart/1105390918119HDSStates2005 Update.pdf. Associated April1, 2005.

Anfinsen, O. G., Bernsten, A. A. S. S. H., Kongsgaard, E., \& Amlie, J. P. (2002). Implantable cardioverter defibrillator and after magnetic resonance imaging. PACE, 25, 1400-1402.

Bänsch, D., Antz, M., Boczor, S., Volkmer, M., Tebbenjohanns, J., \& Karlheinz S., et al, (2002). Primary Prevention of Sudden Cardiac Death in Idiopathic Dilated Cardiomyopathy. The Cardiomyopathy Trial (CAT) Circulation. 105, 1453-1458.

Bhatia, A., Coolly, R., Berger, M., Blanck, Z., Dhala, A., Jasbir, S., et al. (2004). The implantable cardioverter defibrillator: Technology, indications, and impact on cardiovascular survival. Current Problems in Cardiology, 20, 306. 
Bleascade R. A., Ruskin, J. N., \& O'Callaghan, P. A. (2004). The implantable cardioverter defibrillator. In V. Fuster \& E. Braunwald (Eds.). Harrison's advances in cardiology. San Francisco: McGraw-Hill.

Bocka, J. (2004). Automatic External Defibrillation, e Medicine http://www.emedicine.com/emerg/topic698.htm

Brode, S. E, Schwartzman, D., Callans, D. J, Gottlieb, C. D., \& Marchlinski, F. E. (1997). ICD-antiarrhythmic drug and ICD-pacemaker interactions. Journal of Cardiovascular Electrophysiology, 8, 830-842.

Burg, M. M., Lampert, R. J., Batsford, W. \& Jain, D. (2004). Psychological traits and emotion-triggering of ICD shock-terminated arrhythmias. Psychosomatic Medicine, 66, 898-902.

Burns, N., \& Grove, S. K. (2001). The practice of nursing research: Conduct, critique, \& Utilization (4th ed.). New York: Sunders.

Buxton, A. E., Lee, K.I., Fisher, J.D., Josephson, M. E., Prystowsky, E.N., Halfey, G. E. for the Multicenter Unsustained Tachycardia Trail Investigators (1999). A randomized study of the prevention of sudden death in patients with coronary artery disease. New England Journal Medicine, 341, 1882. 1890.

Carisson, E., Olesson, B., \& Hertervig, E. (2002). The role of nurse in enhancing quality of life in patients with an implantable cardioverter-defibrillator: The Swedish experience. Progressive Cardiovascular Nursing, 17, 18-25.

Carnes, C. A., Pickworth, K. K., Votolato, N. A., Raman, S. V. (2004). Elevated defibrillation threshold with venlafaxine therapy. Pharmacotherapy, 24, 1095 1098. 
IST in patients with ICDs 84

Carroll, D. 1., \& Hamilton, G. A. (2005). Quality of life in implanted Cardioverter defibrillator recipients: The impact of device shock. Heart \& Lung, 4, 169-178.

Center for Devices and Radiological Health. (2005). Manufacturer and user facility device experience database (MAUDE). Retrieved March 25, 2005, from http://www.fda.gov/cdrh/maude.html

Champagne, J., Geelen, P., Philippon, F., \& Brugada, P. (2005). Recurrent cardiac events in patients with idiopathic ventricular fibrillation, excluding patients with the Brugada syndrome. $B M C$ Medicine. Retrieved from http://www.biomedcentral.com/1741-7015/3/1prepub.

Chan, N. Y., \& Ho, L. W. (2005). Europace, 7, 193-196.

Charles, D., Swerdlow, M. D., Jianxin Zhang, M.S. (2001). Implantable Cardioverter Defibrillator Shocks: A Troubleshooting Guide, Reviews in Cardiovascular Medicine, 62, 61-72.

Chugh, A., Scharf, C., Hall, B., Cheung, P., Good, E., \& Horwood, L (2005). Prevalence and management of inappropriate detection and therapies in patients with firstgeneration biventricular pacemaker-defibrillators. Pacing Clin Electrophysiology, $28,44-50$.

Connolly, S., Gent M, Roberts R, for the CIDS investigators.(2000).Canadian Implantable Defibrillator Study (CIDS). A randomized trial of the implantable cardioverter defibrillator against amiodarone. Circulation. 101, 1297-1302.

Cragie, B., Loader, R., Burrows and Muncer, S. (2002). Reliability of health information on the net: An examination of experts' ratings, Journal of Medical Internet Research, 4, p. e2. 
Credner, S. C., Klingenheben, T., Mauss, O., Sticherlin, C., Hohnloser, S. H.(1998) Electrical storm in patients with transvenous implantable cardioverter defibrillators: incidence, management and prognostic implications. J Am Coll Cardiol. 32, 1909-1915.

De Meester, A. and Gilles, P-H. (2001). ICD malfunction caused by excessive defibrillation charge time. Journal of Pacing and Clinical Electrophysiology, 24, $518-519$.

DiMarco, J. P. (2003). Implantable cardioverter- defibrillator, New England Journal Medicine, 349, 1836-1847.

Domanski, M. J., Zipes, D. P., \& Schrons, E.(1997). Treatment of sudden death : Current understanding from random trails and future research directions, Circulation, 95, 2694-2699.

Dorwarth, U., Frey, B., Dugas, M., Matis, T., Fiek, M., \& Schmoeckel, et al. (2003). Transvenous defibrillation leads: High incidence of failure during long-term follow-up, Journal of Cardiovascular Electrophysiology, 14, 38.

Dougherty, C. M.(1995). Psychological reactions and family adjustment in shock versus no shock groups after implantation of internal cardioverter defibrillator. Heart \& Lung, 24, 281-291.

Dougherty, C. M., Lewis, F. M., Thompson, E. A., Bear, J. D., \& Kim,W.(2004). Shortterm efficacy of a telephone intervention by expert nurses after an implantable Cardioverter defibrillator. Pacing Clin Electrophysiology, 27, 1594-1602.

Dougherty, C. M,; Pyper, G. P., Frasz, H.A.(2004). Description of a nursing intervention program after an implantable cardioverter defibrillator. Heart Lung. 33, 183-90. 
Dunbar, S. B., Warner, C. D., Purcell, J.A. (1993). Internal cardioverter defibrillator device discharge: Experiences of patients and family members. Heart \& Lung. 22, 494-501.

Dunbar, S. B. (2005). Psychosocial issues of patients with implantable cardioverter defibrillators. American Journal Critical Care, 14, 294-303.

Eder, C., Fullerton, J., Benroth, R., \& Lindsay, S.(2005). Pragmatic strategies that enhance the reliability of data abstracted from medical records. Applied Nursing Research, 18, 50-54.

Egrberg, R.O.(1971). Extending the Scope of Nursing Practice: A Report of the Secretary's Committee to Study Extended Roles for Nurses. U.S. Department of Health Education, and Welfare : Public Health Service.

Fetzer, S.J. (2003). The patient with an implantable cardioverter defibrillator, Journal of the American Society of Peri Anesthesia Nurses. p.8.

Flemme, I., Bolse, K., Ivarsson, A., Jinhage, B.M., Sandstedt, B., Edvardsson, N., Fridlund, B (2001). Life situation of patients with an implantable cardioverter defibrillator: a descriptive longitudinal study. J. Clin Nurs, 10, 563-572.

Fridlund, B., Ivarsson, A., Jinhage, M., Bolse K., Flemme, I.,\& Sandstedt, B.(2000). Patients with implantable cardioverter-defibrillators and their conceptions of the life situation: a qualitative analysis. Journal of Clinical Nursing, 9 Issue 1 Page 37

Garcia-Moran, E, Mont L, Brugada J.(2002). Inappropriate tachycardia detection by a biventricular implantable cardioverter defibrillator. $P A C E, 25,123-124$. Glison, M., Lipchenca, I., Viskin, S., Ballman, K.V., Trusty, J.M., \& Gurevitz, O. S. (2004). Long-term outcome of patients with received implantable cardioverter 
defibrillator for stable ventricular tachycardia, Journal Cardiovascular Electrophysiology, 15, 658-664.

Gold, M. R. (2000). ICD therapy in the new millennium. Cardiology Clinics, 18, 375-389.

Gornick, C. C., Hauser, R. G., Almquist, A. K., Maron, B. J.(2005). Unpredictable implantable cardioverter pulse generator failure due to electrical overstress causing sudden death in a young high risk patient with hypertrophy cardiomyopathy. Heart Rhythm, 2, 681-683.

Gregoratos, G., J., Abrams, J., and Epstein, A. E., Freedam, R. A., David, L., \& Hayes, M.A. et al.(2002). ACC/AHA/NASPE 2002 guideline update for implantation of cardiac pacemakers and antiarrhythmia devices: summary article, Circulation, $106,2145-2161$.

Grimm,W., Flores, B.F., \& Marchlinski, F. E.(1992). Electrocardiograpohically documented unnecessary, spontaneous shocks in 241 patients with implantable cardioverter defibrillators. $P A C E, 15,1667-1673$.

Groh, W. J., \& Foremn, L. D.(1998). Advances in treatment of arrhythmias: Implantable cardioverter-defibrillator. AAFP 1997-1998 Annual Clinical Focus on prevention and management of cardiovascular disease. 1-16.

Gurevitz, O.,Yaacoby, E., \& Segal, E.(2000). Efect of implantable cardioverter defibrillator shocks on QT dispersion. American Journal Cardiology, 86, 11461148.

Healy, E., Goyal, S., Browing, C., Robotis, D., Ramaswamy, K., Rofino-Nadoworany \& Rosenthal, L.(2004). Inappropriate ICD therapy due to proarrhythmic ICD shocks and Hyperpolarization. PACE, 27, 415-416. 
Healy, E., Ngarmukos, T., \& Rosenthal, L.(2002). A case of bad timing: inappropriate implantable cardioverter defibrillator therapy due to a critically placed premature ventricular contraction. Pacing Clin Electrophysiol, 25, 1403-1405.

Jeanne, E., Poole \& Bardy, G. H. (2000). Sudden Cardiac death. In Zipes, D. P., \& Jalife, J. (Eds). Cardiac electrophysiology : From cell to bedside (4 ${ }^{\text {th }}$ ed. pp. 615-640). Philadephia : W. B. Company.

Kamphuis, H.C., Verhoeven, N.W., Leeuw, R., Derksen, R., Hauer, R.N., \& Winnubst, J.A. (2004). ICD: a qualitative study of patient experience the first year after implantation. J Clin Nurs.13, 1008-1016.

Klein, R.C. Raitt, M.H., Wilkoff, B.L. \& AVID Investigators et al (2003) Analysis of implantable cardioverter defibrillator(s) therapy in the AVID trial ICD shocks due to double sensing in patients with bi-ventricular implantable cardioverter defibrillators in the antiarrhythmics verse implantable cardioverter-defibrillators (AVID) trails. J. Cardiovascular Electrophysiology, 14, 940-948.

Kolb, C., \& Schmieder, S.(2002). Inappropriate shock delivery due to interference between a washing machine and an implantable cardioverter-defibrillator, $J$. Cardiovascular Electrophysiology, 7, 255-256.

Kolb, C., Zrenner, B. and Schmitt (2001). Incidence of electromagnetic interference in implantable cardioverter defibrillators. Part I, $P A C E$, 24. 465-468.

Korte, T., Koditz, H., Niehaus, M., Paul, T., \& Tebbenjohanns, J.(2004). High incidence of appropriate and inappropriate ICD therapies in children and adolescents with implantable cardioverter defibrillator. Pacing Clin Electrophysiol. 27, 924-932.

Kuck, K., Cappato, R., Siebels, J., \& Ruppel, F. for the CASH Investigators.(2000). Randomized comparison of antiarrhythmic drug therapy with implantable defibrillators in patients 
resuscitated from cardiac arrest : the Cardiac Arrest Study Hamburg (CASH). Circulation. $102,748-754$.

Kühlkamp, V., and InSync 7272 ICD World Wide Investigators (2002). Initial experience with an implantable cardioverter-defibrillator incorporating cardiac resynchronization therapy, Journal of the American College of Cardiology, 39, $790-797$.

Luria, D. Glikson, M. Brady, P.A. Lexvold, N.Y., Rasmussen, M.J. Hodge, D.O., et al (2001). Predictors and mode of detection of transvenous lead malfunction in implantable defibrillators, American Journal Cardiology, 87, 901-904.

Luderitz, B., Jung, W., A., Diester, A.,Marneros, A. \& Manz, M.(1993). Patient acceptance of the implantable cariverter defibrillator in ventricular tachycardia arrhythmias. PACE, 16, 1815-1821.

Lin, D., Dixit, S., Russio, A. M., and. Hsia, H. H.(2004). Total failure to sense ventricular fibrillation with inappropriate defibrillator, sensitivity adjustment. $P A C E, 27$, $1321-1323$.

Liu, B., Villareal, R. P., Hariharan, R. Rasekh, A., \& Massumi, A.(2003). Inappropriate shock delivery and bioventricular pacing cardiac defibrillators. Texas Heart Institute Journal, 30, 45-49.

Luria, D., Glikson, M., Brady, P. A., Lexvold, N. Y., Rasmussen, M. J. Hodge, D.O., et al (2003). Predictors and mode of detection of transvenous lead malfunction in implantable defibrillators, American Journal Cardiology, 87, 901-904.

Maisel, W.H., Sweeney, M. O., Stevenson, W. G. et al (2001). Recalls and safety alerts involving pacemakers and implantable cardioverter defibrillators, $J A M A, 286$, 793-799. 
Mcbride, B. F., Guerin, D.,White, M. C., \& Klucger, J.(2004). Inappropriate implantable cardioverter discharge following consumption of a dietary weight less supplement, PACE, 27, 117-1320.

Messali, A., Thomas, O., Chauvin, M., Coumel, P., \& Leenhardt, A.(2004). Death due to an implantable cardioverter defibrillator. J. Cardiovasc Electrophysiol, 15, 953956.

Mirowki, K., Reid, P. R., Mower, M. M., Watkins, L., Gott, L. L. et al (1980). Termination of maligant ventriular arrhythmias with an implanted automic defibrillator in human beings. New England Medical Journal, 11, 1278-1286.

Mitchell, L. B., Pineda, E. A., Titus, J.L. Bartosh, P.M. \& Benditt, D.G. (2002). Sudden death in patients with implantable cardioverter defibrillators: the importance of post-shock electromechanical dissociation. Journal American College of Cardiology, 39, 1323-1328.

Moss, A. J., Hall, A. J., Cannom, D. S., Daubert, P., Higgins, S. L., Klei, H., et al. for the Multicenter Automatic Defibrillator Implantable Trail Investigators.(1996). Improved survival with an implantable defibrillator in patients with coronary disease at high risk for ventricular arrhythmia. New England Journal of Medicine, $335,1933-1940$.

Moss, A.J., Zareba, W., \& Hall, W. J.(2002). Prophylactic implantation of a defibrillator in patients with myocardial infarction and reduced ejection fraction. N Engl J Med. 346, 877-883. 
Mower, M. M. \& Reid, P. R.(2001). Historical development of the automatic implantable cardioverter- defibrillator in Implantable cardioverter- defibrillator (Ed). pp.1525.

Naccrareli, G.V.(2004). Implantable cardioverter-defibrillator expanding indications, Current Opinion Cardiology, 19, 317-322.

Nanthakumar, K., Dorian, P., Paquette, M., Greene, M., Edwards, J., Heng, D., Noble, J., Newman, D.(2003). Is inappropriate implantable defibrillator shock therapy predictable? J Interv Card Electrophysiol, 8, 215-220.

Nunian, S.O., Roelke, M., Trouton, T., Kim, Y.H., Sosa-Suarez, G., \& Brooks, J. (1995). Limitation and late complications of third generation implantable cardioverter defibrillators, Circulation, 91, 2204-2213.

Peters, R. W., Cooklin, M., Brockman, R., Steven, R., Shorofsky, S. R., \& Michael, R., (1998).Case Report: Inappropriate shocks from implanted cardioverter defibrillators caused by sensing of diaphragmatic myopotentials, Journal of Interventional Cardiac Electrophysiology, 2, 367-370.

Pickett, III, A. R., Saaverdr, A, P., Ali, M. F., Darbar, ,D., and Rottman, J. N.(2004). Implantable Cardioverter-Defibrillator malfunction due to mechanical failure of the header connection, Journal of Cardiovascular Electrophysiology, 15, 10951099.

Polit, D.F., and Beck, C.T. (2004). Nursing research: Principles and methods. ( $7^{\text {th }}$ Ed). New York : Lippincott Williams \& Wilkins.

Pinski, S.L., \& Fahy, G. J.(1995). The proarrhythmic potential of implantable defibrillators. Circulation, 92, 1651-1664. 
Pinski, S. L. \& Trohman, R. G. (2002). Interference in implanted cardiac device, Part II. PACE, 25, 1496-1509.

Pires, L. A.(2001).Sudden death in patients with implanted defibrillators. Cardiac Electrophysiology Review. 5, 379-384.

Rinaddi, C.A., Simmon,, R.D., Bostock, A. B. Elliot, D. Bcknall, C.A., \& Gill, J.S.S.(2004). A 17 year experience of inappropriate shock therapy in patients with implantable cardioverter-defibrillators: are we getting better? Heart, 90, 330-331.

Rajawat,Y. S., Patel,V. V., Gerstenfeld, E. P., Nayak, H., and Marchinski, F. E. (2004) Advantages and pitfalls of combining device-based and pharmacologic therapies for the treatment of ventricular arrhythmias: Observations from a tertiary referral center. Pace, 27, 1670-1681.

Rosenqvist, M., Beyer, T., Block, M. Den Dulk, K., Minten, J., Lindemans, F., On behalf of the European 729 Jewel ICD Investigators. (1998). Adverse events with transvenous implantable cardioverter- defibrillator, Circulaion, 98, 663-670.

Russio, A.M. Nayak, H., Verdino, R. Springman, J., \& Tenfeld, E. G. ,et al (2003). Implantable cardioverter defibrillator events in patients with asymptomic nonsustained ventricular tachycardia: Is device implantation justified ? $P A C E, 26$, 2289-2295.

Sabate, X., Moure, C., Nicolas, J., Sedo, M., \& Navarro, X.(2001). Washing machine associated $50 \mathrm{~Hz}$ detected as ventricular fibrillation by an implanted cardioverter defibrillator. Pacing Clin Electrophysiol. 24(8 Pt 1), 1281-1283.

Schimpf, R., Wolpert, C., Bianchi, F, (2003). Congenital short QT syndrome 
and implantable cardioverter defibrillator treatment: Inherent risk for inappropriate shock delivery. J Cardiovasc Electrophysiol, 14, 1273-1277.

Schreieck, J., Zrenne, K., Kolb, C., Ndrepepa, G., Schmitt, C.(2001). Inappropriate shock delivery due to ventricular double detection with a biventricular pacing implantable cardioverter defibrillator. Pacing Clin Electrophysiol. 24, 1154-1157.

Schulte, B., Sperzel, J., Schwarz, T.(2000). Detection of ventricular fibrillation in implantable defibrillators with automatic gain controlamplifiers: Effects of programming sensitivity. Europace, 2, $160-162$.

Sears, S. F., (2002).Quality of life and psychological function of ICD patients. Heart, 87, 488-493.

Seidl, K. and Senges, J.(2003). Worldwide utilization of implantable cardioverter defibrillators : Now and in the Future. Cardiac Electrophysiology Review, 7, 5-13

Sergo, P. \& Gerard, F.(1995).The proarrhythmic potentisl of implantable cardioverter defibrillator. Circulation, 92, 1651-1664.

Shea, J. B.(2004). Quality of life issues in patients with implantable cardiovereter defibrillators: Driving, occupation, and recreation. $A A C N$, Clinical Issues, 15, 478-489.

Sheldon R, Connolly S, Krahn, A. (2000). Identification of patients most likely to benefit from implantable cardioverter defibrillator therapy. The Canadian implantable defibrillator study. Circulation, 101, 1660-1664.

Singer, I.(1994). Implantable cardioverter defibrillator. New York: Future Publishing Company. 
IST in patients with ICDs 94

Sperelakis, N., Kurachi, Y., Terzic, A. \& Cohen, M.V.(Eds).(2001). Heart physiology and pathophysiology. San Diego : Academic Press, A Harcourt Science and Technology Company.

Spector, P. S.(2005). Diagnosis and management of sudden cardiac death, Heart, 91, 408413.

Steinbrook, R.(2005). The Controversy over Guidant's implantable defibrillators. The New England Journal of Medicine, 353, 221-224.

Stevenson, W.G., Chaitma, B. R., Ellenbogen, K. A. et al (2004). Clinical assessment and Management of patients with implanted cadrioverter - defibrllators presening to nonelectrophysiologists. Circulation, 110, 3866-3869.

Sweesy, M. W., Holand, J.L., \& Smith, K.W. (2004). Electromagnetic interference in cardiac rhythm management devices, AACN Clinical Issues, 15, 391-403.

Sweeney, M.O., Wathen, M.S., Volsi, K., Abdalla, I., Degroot, P.J., \& Otterness, M. F., (2005). Appropriate and inappropriate ventricular therapies, quality of life, and mortality among primary and secondary preventaion implantable Cardioverter defibrillator patients- Results from the pacing fast VT Reduces Shock ThErapies (PainFREE Rx II)Trail, Circulation, 111, 2898- 2905.

Swerdlow, C. D., \& Zhang, J. (2001). Implantable Cardioverter Defibrillator Shocks: A Troubleshooting Guide. Review in Cardiovascular Medicine. 2, 61-72.

The Antiarrhythmics Versus Implantable Defibrillators (AVID) Investigators (1997). A comparison of antiarrhythmic drug therapy with implantable defibrillators in patients resuscitated from near fatal ventricular arrhythmias, $N$ Engl J Med, 337. $1576-1583$. 
The Cardiac Arrhythmia Suppression Trial II Investigators.(1992). Effect of the antiarrhytmic agent moricizine on survival after myocardial infarction. The New England Journal of Medicine 327, 227-233.

Theuns, D., Klootwijk, P. J., Simoons, M. L., and Jordaens, L. J.(2005). Clinical variables predicting inappropriate use of implantable cardioverter-defibrillator in patients with coronary heart disease or nonischemic dilated cardiomyopathy. American Journal of Cardiology,95, 271-274.

Weber, M., Boecker, D., \& Block, M., et al (1996). Inappropriate ICD therapies: incidence, causes, risk factors and prevention. In : E. Adonarto (Ed). Therapies or cardiac arrhythmias in 1996: Where are we going? Vol. I, Roma, Italy, Edizini Luigi Pozzi, 183194.

White, M. M. (2002). Psychosocial impact of the implantable cardioverter defibrillator : Nursing implications. Journal of Cardiovascular Nursing, 16, 53-61.

Woods, S L., Froelicher, E. S., Motzer, S. U., \& Bridges, E. J. (Eds, $4^{\text {th }}$ ed) (2005). Cardiac nursing, New York: Williama \& Wilkins.

Zipes, D. P. , \& Wellens, H. J. J. (1998). Sudden cardiac death, Circulation, 98, 23342351.

Zipes, D. P., Libby, P., Bonow, R. O., \& Braunwald, E. (Eds) (2005). Braunwald's heart disease: A textbook of cardiovascular medicine, $\left(7^{\text {th }}\right.$ Ed). Philadelphia, PA: Elsevier Saunders. 


\section{Appendix A}

Table 1

\section{Trails of ICD Therapy for the Secondary Prevention of SCD}

Trails of ICD Therapy for the Secondary Prevention of SCD

\begin{tabular}{|c|c|c|c|}
\hline Study /Study Period & $\begin{array}{c}\text { Population Characteristics, } \\
\mathrm{N}=\text { total }\end{array}$ & End Point (s) & Key Finding(s) \\
\hline $\begin{array}{l}\text { AVID/1993-1997 } \\
\text { Antiarhythmics vs. } \\
\text { Implantable } \\
\text { Defibrillator }\end{array}$ & $\begin{array}{l}\text { - N=1016 } \\
\text {-Survival of VF, } \\
\text {-SMVT with near syncope, } \\
\text {-SMVT with EF } \leq 40 \% \& \\
\text { symptoms. } \\
\text {-ICD therapy vs Antiarrhythmic } \\
\text { (Amiodarone, Sotalol) therapy }\end{array}$ & $\begin{array}{l}\text { - Total mortality } \\
\text { - Mode of death } \\
\text { - Quality of life } \\
\text { - Cost benefit }\end{array}$ & $\begin{array}{l}\text {-The ICD group experienced a } 39 \% \\
\text { reduction death in the first year with a } \\
27 \% \text { and } 31 \% \text { reduction in years two } \\
\text { and three. } \\
\text { - Enrollment was discontinued } \\
\text { prematurely because of a significant } \\
\text { improvement overall survival with ICD. }\end{array}$ \\
\hline $\begin{array}{l}\text { CIDS/ 1990-1998 } \\
\text { Canadian Implantable } \\
\text { Defibrillator Study }\end{array}$ & $\begin{array}{l}-\mathrm{N}=659 \\
\cdot \text { Resuscitated after out-of hospital } \\
\text { cardiac arrest } \\
\text {-documented VF } \\
\text {-SMVT with syncope } \\
\text {-SMVT with EF<35\% } \\
\cdot \text { ICD }(n=328) \text { vs } \\
\text { amiodarone }(n=331)\end{array}$ & $\begin{array}{l}\text {-Primary end point: } \\
\text { All causes mortality } \\
\text {-Secondary end point: } \\
\text { arrhythmia death }\end{array}$ & $\begin{array}{l}\text { A relative reduction occurred in all } \\
\text { cause mortality of } 19.7 \% \text { in ICD group. } \\
\text { A } 33 \% \text { reduction occurred in } \\
\text { amiodarone group(this reduction did not } \\
\text { reach statistical significance). } \\
\text { - Result supports ICD is better than } \\
\text { Amiodarone in the treatment of patients } \\
\text { with MSVT or resuscitated cardiac } \\
\text { arrest. }\end{array}$ \\
\hline $\begin{array}{l}\text { CASH /1987-1998 } \\
\text { Cadiac Arrest Study } \\
\text { Hamburg }\end{array}$ & $\begin{array}{l}\cdot N=288 \\
\text { - Resuscitated after cardiac arrest } \\
\text { secondary to documented } \\
\text { ventricular arrhythmia } \\
\text {-ICD }(n=99) \text { vs } \\
\text { amiodarone }(n=92), \text { metoprolol } \\
(n=97), \& \text { propafenone }(n=58, \\
\text { propafenone discontinued } 3 / 92)\end{array}$ & $\begin{array}{l}\text {-Primary endpoint: } \\
\text { Total mortality } \\
\text {-Secondary endpoints: } \\
\text { Recurrences of cardiac } \\
\text { arrest requiring CPR } \\
\text { * Recurrences of unstable } \\
\text { Angina }\end{array}$ & $\begin{array}{l}\text { Preliminary results showed that } \\
\text { propafenone treatment is less effective } \\
\text { than ICD treatment. Therefore, this arm } \\
\text { was suspended. The ICD group } \\
\text { experienced a } 24 \% \text { relative reduction in } \\
\text { mortality with amiodarone /metoprolol } \\
(p=0.081) \text {, non significant. }\end{array}$ \\
\hline
\end{tabular}


Table 2

Summary of ICD Trails for the Primary Prevention of SCD

\begin{tabular}{|c|c|c|c|c|}
\hline $\begin{array}{c}\text { Trail / Study } \\
\text { period }\end{array}$ & $\begin{array}{c}\text { Study Population } \\
\text { N=Total }\end{array}$ & Study Group & Endpoint(s) & Key Finding(s) \\
\hline $\begin{array}{l}\text { CABG Patch } \\
\text { /1990-1997 } \\
\text { Coronary Artery } \\
\text { Bypass Graft } \\
\text { patch trail }\end{array}$ & $\begin{array}{l}-\mathrm{N}=900, \text { age }<80 \\
-\mathrm{EF} \leq 36 \% \text { \& } \\
\text {-Abnormalities on - } \\
\text { average signal ECG } \\
\text { - Randomly assigned in } \\
\text { OR after CABG } \\
\text { - CABG+ ICD, } \mathrm{n}=446 \\
\text { CABG alone, } \mathrm{n}=454\end{array}$ & $\begin{array}{l}\text { ICD vs } \\
\text { conventional } \\
\text { medical therapy }\end{array}$ & $\begin{array}{l}\text { Total } \\
\text { mortality }\end{array}$ & $\begin{array}{l}\text {-The trail was prematurely terminated because } \\
\text { mortality was equal in the CABG plus ICD }(101 \\
\text { deaths) compare CABG alone } 95 \text { deaths; } \\
\text { demonstrated no benefit of the prophylactic } \\
\text { insertion of an ICD in patients with an ischemic } \\
\text { burden and a depression EF undergoing } \\
\text { appropriated coronary revascularization. }\end{array}$ \\
\hline $\begin{array}{l}\text { MADIT I } \\
\text { 1990-1996 } \\
\text { Multicenter } \\
\text { Automatic } \\
\text { Defibrillator } \\
\text { Implantation } \\
\text { Trail }\end{array}$ & $\begin{array}{l}\cdot \mathrm{N}=196 \text {, age } 25-80 \\
\cdot \text { Prior MI, } \\
\text {-NYHAclass I-III } \\
\text {-CHF, LVEF } \leq 35 \% \\
\text {-NVST, VT } 3 \text { to } 30 \\
\text { beats; -Inducible and } \\
\text { non suppressible VT/ } \\
\text { VF on EPS, not } \\
\text { suppressed by IV } \\
\text { procainamide) } \\
\text {-101 drug therapy ( } 80 \\
\text { on Amiodarone) } \\
\text { - } 95 \text { ICD }\end{array}$ & $\begin{array}{l}\text { ICD vs } \\
\text { conventional } \\
\text { therapy } \\
\text { (Antiarrhythmia } \\
\text { Drugs) }\end{array}$ & $\begin{array}{l}\text { Total } \\
\text { mortality } \\
\text { Cost - } \\
\text { effectiveness }\end{array}$ & $\begin{array}{l}\cdot 39(39 \%) \text { deaths in antiarrhythmic group vs } \\
15(21 \%) \text { ICD group } \\
\text { Hazard ratio, } 0.46 ; \mathrm{CI}, 026-0.82 ; \mathrm{p}=0.009) \\
\text { Significant reduction in death from all causes in } \\
\text { ICD group } \\
\cdot \text { ICD cost effective }\end{array}$ \\
\hline
\end{tabular}




\begin{tabular}{|c|c|c|c|c|}
\hline $\begin{array}{c}\text { Trail / Study } \\
\text { Period }\end{array}$ & $\begin{array}{c}\text { Study Population } \\
\mathrm{N}=\text { total }\end{array}$ & Study Groups & Endpoint(s) & Key Finding(s) \\
\hline $\begin{array}{l}\text { DEFINITE/ } \\
2000-2003 \\
\text { Defibrillator } \\
\text { in Nonischemic } \\
\text { Cardiomyopathy } \\
\text { Treatment } \\
\text { Evaluation }\end{array}$ & $\begin{array}{l}\mathrm{N}=458 \\
\cdot \text { Symptomic CHF+ } \\
\text { nonischemic } \\
\text { cardiomyophy } \\
{[\mathrm{EF} \leq 35 \%]} \\
>10 \text { PVCs/hr or NSVT } \\
\cdot \text { Optimal medical } \\
\text { therapy, } \mathrm{n}=229 \text {. } \\
\text { - Optimal therapy + } \\
\text { ICD therapy, } n=229 \text {. }\end{array}$ & $\begin{array}{l}\text { ICD vs } \\
\text { conventional } \\
\text { medical therapy } \\
\text { (Drug Therapy } \\
\text { only) }\end{array}$ & $\begin{array}{l}\text {-The Primary } \\
\text { End Point: } \\
\text { Total } \\
\text { mortality } \\
\text {-The } \\
\text { Secondary } \\
\text { end point : } \\
\text { All kinds of } \\
\text { death }\end{array}$ & $\begin{array}{l}\text { - Death from any cause; in } \\
\text {-ICD group }(n=28) \text {, } \\
\text {-Conventional medical therapy }(n=40) \\
\text {-Sudden death from arrhythmia in } \\
\text {-ICD group }(n=3) \text {, } \\
\text {-Conventional medical therapy }(n=14) \\
\text { *Significant reduction in overall mortality } \\
\text { in ICD group. } \\
\text { ICD decreased mortality by } 34 \%\end{array}$ \\
\hline $\begin{array}{l}\text { COMPANION } \\
(01 / 2000-11 / 2002) \\
\text { Comparison of } \\
\text { Medical Therapy, } \\
\text { Pacing and } \\
\text { Defibrillation in } \\
\text { Heart Failure }\end{array}$ & $\begin{array}{l}1520 \text { patients } \\
\text { Heart failure patients } \\
\text { (NYHA class III-IV) } \\
\text { with EF } \leq 35 \%, Q R S \geq \\
120 \mathrm{~ms}, \text { PR interval > } \\
150 \mathrm{~ms}\end{array}$ & 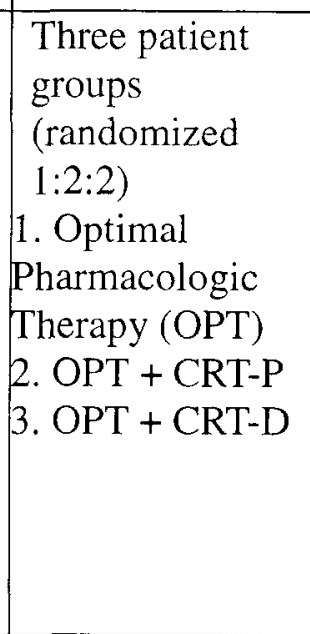 & $\begin{array}{l}\text { - Combination } \\
\text { of all-cause } \\
\text { mortality or } \\
\text { first } \\
\text { hospitalizatio } \\
\mathrm{n} * \text { as } \\
\text { measured by } \\
\text { time to first } \\
\text { event }\end{array}$ & $\begin{array}{l}\text { - A pacemaker with CRT capabilities (CRT- } \\
\text { P), in combination with OPT, reduced the } \\
\text { risk of all-cause mortality or first } \\
\text { hospitalization* by } 19 \% \text { when compared } \\
\text { with OPT alone. } \\
\text { - A defibrillator with CRT capabilities } \\
\text { (CRT-D), in combination with OPT, } \\
\text { reduced the risk of all-cause mortality or } \\
\text { first hospitalization* by } 20 \% \text { when } \\
\text { compared with OPT alone. } \\
\text { - CRT-D, in combination with OPT, } \\
\text { reduced the risk of all-cause mortality by } \\
36 \% \text { when compared with OPT alone }\end{array}$ \\
\hline
\end{tabular}




\begin{tabular}{|c|c|c|c|c|}
\hline $\begin{array}{l}\text { Trail / Study } \\
\text { Period }\end{array}$ & $\begin{array}{c}\text { Study Population } \\
\mathrm{N}=\text { total }\end{array}$ & Study Groups & Endpoint(s) & Key Finding(s) \\
\hline $\begin{array}{l}\text { SCD - HeFT/ } \\
1997-2003 \\
\text { The Sudden } \\
\text { Cardiac Death } \\
\text { Heart Failure Trail }\end{array}$ & $\begin{array}{l}\mathrm{N}=2521 \\
\mathrm{NYHA} \text { II-III, CHF, } \\
\mathrm{EF} \leq 35 \% \\
\text { ICD and conventional } \\
\text { therapy }(\mathrm{n}=829) \\
\text { Amioderone and } \\
\text { conventional therapy } \\
(\mathrm{n}=845) . \\
\text { Placebo and } \\
\text { conventional therapy } \\
(\mathrm{n}=847)\end{array}$ & $\begin{array}{l}\text { ICD and } \\
\text { conventional } \\
\text { therapy ( } \mathrm{n}= \\
829) \text { vs } \\
\text { Amioderone \& } \\
\text { conventional } \\
\text { therapy }(\mathrm{n}=845) \\
\text { vs Placebo \& } \\
\text { conventional } \\
\text { therapy }(\mathrm{n}=847)\end{array}$ & $\begin{array}{l}\text { Total } \\
\text { Mortality }\end{array}$ & $\begin{array}{l}\text { - Amiodarone has no favorable effect on } \\
\text { survival. single lead. } \\
\text { - Shock only ICD therapy reduces overall } \\
\text { mortality by } 23 \% \text {. } \\
\text { Conclusions: NIDCM treated with ACE } \\
\text { inhibitors and beta-blockers, the } \\
\text { implantation of a cardioverter-defibrillator } \\
\text { significantly reduced the risk of SCD from } \\
\text { arrhythmia and was associated with no } \\
\text { significant reduction in the risk of death } \\
\text { from any cause. }\end{array}$ \\
\hline
\end{tabular}

\section{Abbreviations:}

$\mathrm{CAD}=$ coronary artery disease $\mathrm{CHF}=$ congestive heart failure;

EPS = electrocardiphysiology Study; ICD = Implantable Cardioverter- Defibrillator;

EF $($ LVEF $)=$ left ventricular ejection fraction; NYHA = New York Heart Association Functional Class;

NIDCM = nonischemic dilated cardiomyopathy;

NSVT $=$ non sustained ventricular tachycardia; $\mathrm{PVC}=$ premature ventricular contraction;

SMVT = sustained monomorphagic ventricular tachycardia; VT= ventricular tachycardia.

$\mathrm{CRT}-\mathrm{P}=$ cardiac resynchronization therapy - pacemaker

$\mathrm{CRT}-\mathrm{D}=$ cardiac resynchronization therapy - defibrillation 


\section{Appendix B \\ 2002 Indications for Implantable Cardioverter - Defibrillator Therapy (ACC/AHA/NASPE) Practice Guidelines}

Class I: Conditions for which there is evidence and/or general agreement that a given procedure or treatment is beneficial, useful, and effective.

Class II: Conditions for which there is conflicting evidence and/or a divergence of opinion about the usefulness/efficacy of a procedure or treatment.

Class IIa: Weight of evidence/opinion is in favor of usefulness/efficacy.

Class IIb: Usefulness/efficacy is less well established by evidence/opinion.

Class III: Conditions for which there is evidence and/or general agreement that a

procedure/treatment is not useful / effective and in some cases may be harmful.

Class I indications per level of A, B or C

A. Data were derived from multiple randomized clinical trails involving a large number of subjects.

B. Data were derived from a limited number of trails involving comparatively small of patients from well designed data analysis data analysis of nonrandomized studies or observational data registries.

C. Consensus of expert opinions was the primary source or recommendation.

Class III indications are patients in whom ICD therapy is no appropriate.

$\mathrm{CAD}$, coronary artery disease; EP. electrophysiology

Class I

1. Cardiac arrest due to VF or VT not due to a transient or reversible cause. (Level A)

2. Spontaneous sustained VT in association with structural heart disease. (Level B)

3. Syncope of undetermined origin with clinically relevant, hemodynamically significant sustained VT or VF induced at electrophysiologic study when drug therapy is ineffective, not tolerated, or not preferred. (Level B)

4. Nonsustained VT in patients with coronary disease, prior MI, LV dysfunction, and inducible VF or sustained VT at electrophysiologic study that is not suppressible by a Class I antiarrhythmic drug. (Level $A$ )

5. Spontaneous sustained VT in patients without structural heart disease not amenable to other treatments. (Level C)

Class IIa

Patients with left ventricular ejection fraction of less than or equal to $30 \%$ at least 1 month post myocardial infarction and 3 months post coronary artery revascularization surgery. (Level B)

Class IIb

1. Cardiac arrest presumed to be due to VF when electrophysiologic testing is precluded by other medical conditions. (Level C)

2. Severe symptoms (e.g., syncope) attributable to ventricular tachyarrhythmias in patients awaiting cardiac transplantation. (Level C)

3. Familial or inherited conditions with a high risk for life-threatening ventricular tachyarrhythmias such as long-QT syndrome or hypertrophic cardiomyopathy. (Level B) 
4. Nonsustained VT with coronary artery disease, prior MI, LV dysfunction, and inducible sustained VT or VF at electrophysiologic study. (Level B)

5. Recurrent syncope of undetermined origin in the presence of ventricular dysfunction and inducible ventricular arrhythmias at electrophysiologic study when other causes of syncope have been excluded. (Level C)

6. Syncope of unexplained origin or family history of unexplained sudden cardiac death in association with typical or atypical right bundle-branch block and ST segment elevations (Brugada syndrome). (Level C)

Class III

1. Syncope of undetermined cause in a patient without inducible ventricular tachyarrhythmias and without structural heart disease. (Level C)

2. Incessant VT or VF. (Level C)

3. VF or VT resulting from arrhythmias amenable to surgical or catheter ablation; for example, atrial arrhythmias associated with the Wolff-Parkinson- White syndrome, right ventricular outflow tract VT, idiopathic left ventricular tachycardia, or fascicular VT. (Level C)

4. Ventricular tachyarrhythmias due to a transient or reversible disorder (e.g., AMI, electrolyte imbalance, drugs, or trauma) when correction of the disorder is considered feasible and likely to substantially reduce the risk of recurrent arrhythmia. (Level B)

5. Significant psychiatric illnesses that may be aggravated by device implantation or may preclude systematic follow-up. (Level $C$ )

6. Terminal illnesses with projected life expectancy less than 6 months. (Level $C$ )

7. Patients with coronary artery disease with LV dysfunction and prolonged QRS duration in the absence of spontaneous or inducible sustained or nonsustained VT who are undergoing coronary bypass surgery. (Level $B$ )

8. NYHA Class IV drug-refractory congestive heart failure in patients who are not candidates for cardiac transplantation. (Level C)

From "ACC/AHA/NASPE 2002 guideline update for implantation of cardiac pacemakers and antiarrhythmia devices: Summary article," by G., J. Gregoratos, J. Abrams, A .E. Epstein, , 2002, Circulation, 106, pp. 2145-2161. 


\section{Appendix C}

Nursing Research Related to Care of ICD Recipients (Studies are presented in Chronological Order)

\begin{tabular}{|c|c|c|c|c|}
\hline Author/Year & Purpose & Study Design & $\begin{array}{l}\text { Subjects } \\
N=\text { total }\end{array}$ & $\begin{array}{c}\text { Major Findings/Suggestions R/T } \\
\text { Education }\end{array}$ \\
\hline $\begin{array}{l}\text { Fridlund } \\
\text { et al } \\
12000\end{array}$ & $\begin{array}{l}\text { Patients with ICDs and } \\
\text { their conceptions of their } \\
\text { life situations }\end{array}$ & $\begin{array}{l}\text { A 12-month descriptive } \\
\text { longitudinal study was } \\
\text { carried out during a } \\
\text { period of } 48 \text { months. } \\
\text { fibrillator Questionnaire }\end{array}$ & $\begin{array}{l}\mathrm{N}=46 \\
\text { ICD recipients }\end{array}$ & $\begin{array}{l}\text { Overall uncertainty showed a } \\
\text { decrease over time. A statistically } \\
\text { significant difference was found } \\
\text { within the domain "uncertainty" } \\
\text { related to information, suggesting } \\
\text { the need for more education in } \\
\text { teaching skills for health care } \\
\text { personnel. }\end{array}$ \\
\hline $\begin{array}{l}\text { Cowan } \\
\text { et al } \\
12001\end{array}$ & $\begin{array}{l}\text { To evaluate the effects of } \\
\text { biofeedback training used } \\
\text { in cardiovascular health } \\
\text { education }\end{array}$ & $\begin{array}{l}\text { Experimental study on } \\
\text { bio-feedback training } \\
\text { used in cardiovascular } \\
\text { health education } \\
\text { Follow-up }=2 \text { years }\end{array}$ & $\begin{array}{l}N=133 \\
\text { Experimental group } \\
(n=67) \\
\text { Usual care }(n=66)\end{array}$ & $\begin{array}{l}\text { Psychosocial therapy significantly } \\
\text { reduced risk of cardiovascular } \\
\text { death in SCD survivals. }\end{array}$ \\
\hline $\begin{array}{l}\text { Flemme } \\
\text { et al } \\
12001\end{array}$ & $\begin{array}{l}\text { To describe changes in } \\
\text { the life situation of } \\
\text { patients with an ICD over } \\
\text { a period of } 1 \text { year }\end{array}$ & $\begin{array}{l}\text { Descriptive longitudinal } \\
\text { study }\end{array}$ & $\begin{array}{l}\mathrm{N}=56 \\
\text { Consecutive ICD } \\
\text { recipients }\end{array}$ & $\begin{array}{l}\text { Regarding their overall life } \\
\text { situations, patients expressed } \\
\text { increased satisfaction as well as } \\
\text { less uncertainty and fear. The } \\
\text { research indicates that patients } \\
\text { need more information about } \\
\text { typical changes in patients' life } \\
\text { situations after ICD implantation. }\end{array}$ \\
\hline
\end{tabular}




\begin{tabular}{|c|c|c|c|c|}
\hline $\begin{array}{c}\text { Author } \\
\text { /Year }\end{array}$ & Purpose & Study Design & $\begin{array}{l}\text { Subjects } \\
\mathrm{N}=\text { Total }\end{array}$ & $\begin{array}{c}\text { Major Findings/Suggestions R/T } \\
\text { Education }\end{array}$ \\
\hline $\begin{array}{l}\text { Carlsson } \\
\text { et al } \\
12002\end{array}$ & $\begin{array}{l}\text { To describe how well the } \\
\text { ICD recipients cope with } \\
\text { their situations when they } \\
\text { have the support of a } \\
\text { nurse, and } \\
\text { contrast this data with } \\
\text { that from a control group } \\
\text { receiving conventional } \\
\text { information given by } \\
\text { physicians. }\end{array}$ & $\begin{array}{l}\text { Experimental study } \\
\text { questionnaire, interviews, } \\
\text { and observations. }\end{array}$ & $\begin{array}{l}\mathrm{N}=20 \\
\text { Experimental group- } \\
\text { Support by nurse } \\
(\mathrm{n}=10) \text {. } \\
\text { Control group- } \\
\text { Received } \\
\text { conventional patient } \\
\text { education by a } \\
\text { physician }(\mathrm{n}=10) \text {. }\end{array}$ & $\begin{array}{l}\text { Sleep disturbances were the } \\
\text { greatest problem in both the } \\
\text { study group and the control } \\
\text { group before ICD implantation. } \\
\text { The control group showed need } \\
\text { for more information regarding } \\
\text { the function of the ICD device. } \\
\text { By means of a questionnaire, } \\
\text { interviews and observations, the } \\
\text { study revealed great need for } \\
\text { information, and therefore that } \\
\text { planning ways to create this } \\
\text { kind of education is important. }\end{array}$ \\
\hline $\begin{array}{l}\text { Albarran } \\
\text { et al. } \\
12004\end{array}$ & $\begin{array}{l}\text { To explore the nature of } \\
\text { patients' partners' } \\
\text { experiences from the pre- } \\
\text { ICD implantation phase } \\
\text { up until a maximum of } \\
20 \text { months at home. }\end{array}$ & $\begin{array}{l}\text { Qualitative study } \\
\text { based on a semi-structured } \\
\text { schedule }\end{array}$ & $\begin{array}{l}\text { Eight partners } \\
\text { cohabiting with a } \\
\text { recipient of an ICD }\end{array}$ & $\begin{array}{l}\text { Four themes representing } 11 \\
\text { categories conceptualized the } \\
\text { partners' experiences, including: } \\
\text { Acknowledging the patient's } \\
\text { need for the device, reactions to } \\
\text { the device, Feeling grateful, } \\
\text { Waiting for the shock, Knowing } \\
\text { what to do to safeguard the } \\
\text { patient, and Returning to } \\
\text { normality. }\end{array}$ \\
\hline
\end{tabular}




\begin{tabular}{|c|c|c|c|c|}
\hline Author/ Year & Purpose & Study Design & $\begin{array}{l}\text { Subjects } \\
\mathrm{N}=\text { Total }\end{array}$ & $\begin{array}{c}\text { Major Findings/Suggestions } \\
\text { R/T Education }\end{array}$ \\
\hline $\begin{array}{l}\text { Dougherty } \\
\text { et al } \\
/ 2004 \mathrm{a}\end{array}$ & $\begin{array}{l}\text { 1) To describe the } \\
\text { domains of concerns of } \\
\text { intimate partners of } \\
\text { sudden cardiac death } \\
\text { (SCD) during the first } \\
\text { year after ICD } \\
\text { implantation; } \\
\text { 2) To outline the strategies } \\
\text { used by partners of SCD } \\
\text { survivors in dealing with } \\
\text { the concerns and demands } \\
\text { of recovery during the } \\
\text { first year after ICD } \\
\text { implantation. }\end{array}$ & $\begin{array}{l}\text { Secondary analysis of } \\
\text { interview data collected } \\
\text { for the primary study } \\
\text { entitled, "Family } \\
\text { Experiences following } \\
\text { Sudden Cardiac } \\
\text { Arrest" }\end{array}$ & $\begin{array}{l}\mathrm{N}=15 \\
\text { families who met the } \\
\text { inclusion criteria } \\
\text { (sudden cardiac } \\
\text { death survival) }\end{array}$ & $\begin{array}{l}\text { Eight domains of concerns: } \\
\text { 1) Care to ensure survival; 2) } \\
\text { The partner's self-care; 3) The } \\
\text { relationship; 4) The ICD; } \\
\text { 5) Money matters; 6) The } \\
\text { future; 7) Health care providers } \\
\text { and family, } \\
\text { or, education \& support sources; } \\
\text { 1) Information on the function } \\
\text { of the ICD; 2) Normal } \\
\text { progression of physical and } \\
\text { emotional recovery experiences; } \\
\text { 3) Safety and maintenance of } \\
\text { the ICD; 4) Activities of daily } \\
\text { living with the ICD; 5) } \\
\text { Strategies to assist with the } \\
\text { partner's self-care. }\end{array}$ \\
\hline $\begin{array}{l}\text { Dougherty } \\
\text { et al } \\
12004 \mathrm{~b}\end{array}$ & $\begin{array}{l}\text { To evaluate the effects of } \\
\text { a short-term intervention } \\
\text { for the initial ICD } \\
\text { recipients }\end{array}$ & $\begin{array}{l}\text { Experimental. } \\
\text { A structured telephone } \\
\text { intervention delivered } \\
\text { during the first } 8 \text { weeks } \\
\text { after ICD therapy by } \\
\text { expert cardiovascular } \\
\text { nurses }\end{array}$ & $\begin{array}{l}\mathrm{N}=168 \\
\text { Individuals who had } \\
\text { experienced a first } \\
\text { SCA or life- } \\
\text { threatening } \\
\text { ventricular } \\
\text { arrhythmia requiring } \\
\text { ICD implantation }\end{array}$ & $\begin{array}{l}\text { Decreased ICD related physical } \\
\text { symptoms and anxiety, and } \\
\text { increased SCA knowledge over } \\
3 \text { months. }\end{array}$ \\
\hline
\end{tabular}


Appendix D

\section{ICD INAPPROPRIATE SHOCK THERAPY STUDY DATA SHEET}

\section{Demographic and Clinical Characteristics}

Patient Information

Age

Diagnosis / Indication $\mathrm{VF} / \mathrm{VT}$ MUSTT/MADITII DCM NIDCM $\mathrm{CHF}$ Other
$\operatorname{Sex} M$
F

Subject Code
Clinical History / Cardiac History before

\section{History}
Underlying Disease
a. Heart disease -
i) Other structural heart disease
ii) Non structure heart disease
b. Heart disease severity
i) Left ventricular ejection fraction
ii) NYHA Functional Classes
c. Other significant disease

\section{Device Information}

Manufacturer : Guidant(G) Medtronic(M) St. Jude (S) Implantation date(s) mode model Programmer

\section{Shock Episode (s) History}

Incidence of Shock Appropriate shock Inappropriate shock

\section{Description(s) of Inappropriate Shock(s)}

1.Energy of shock Joul

2.How was device programmed at the time of shock

3.Drug(s) (Medications) at the time of inappropriate shock
a. Anti Antiarrhythmic Therapy (AA medications)
b. Amiodarone
4.Symptoms during at the time of inappropriate shock
5. Factors of inappropriate shock

\section{Termination of inappropriate shock}


IST in Patients with ICDs 109

APPENDIX F

Approval Letter From the Committee of Human Research - University of California San Diego Medical Center 


\section{UNIVERSITY OF CALIFORNIA, SAN DIEGO HUMAN RESEARCH PROTECTIONS PROGRAM}

TO: Dr. Ulrika Birgersdotter-G Mailcode: 8411

RE: $\quad$ Project $\# 051123 \mathrm{X}$

Incidence and Clinical Predictor of Risk Factors for Inappropriate Shock in

Patients With Implantable Cardioverter-Defibrillators (ICD)

Dear Dr. Birgersdotter-Green:

The above-referenced project was reviewed and approved on $9 / \mathbf{1 / 2 0 0 5}$ by one of this institution's Institutional Review Boards in accordance with the requirements of the Code of Federal Regulations on the Protection of Human Subjects (45 CFR 46 and 21 CFR 50 and 56), including its relevant Subparts. The IRB determined that waiver of informed consent may be granted for this project as it meets the requirements outlined in 45 CFR 46.116(d). This approval, based on the degree of risk, is for 365 days from the date of IRB review and approval unless otherwise stated in this letter. The regulations require that continuing review be conducted on or before the 1-year anniversary date of the IRB approval, even though the research activity may not begin until some time after the IRB has given approval. In addition, a waiver of individual authorization for use of Protected Health Information (PHI) was granted by the Institutional Review Board as stipulated by the HIPAA Privacy Rule, 45 CFR 164 section $512(\mathrm{I})$.

The Institutional Review Board determined that the proposed research satisfies following criteria:

1. The use or disclosure of PHI involves no more than minimal risk.

2. Granting of waiver will not adversely affect privacy rights and welfare of the individuals whose records will be used.

3. The project could not practicably be conducted without a waiver.

4. The project could not practicably be conducted without use of PHI.

5. The privacy risks are reasonable relative to the anticipated benefits of research.

6. An adequate plan to protect identifiers from improper use and disclosure is included in the research proposal.

7. An adequate plan to destroy the identifiers at the earliest opportunity, or justification for retaining identifiers, is included in the research proposal.

8. The project plan includes written assurances that PHI will not be re-used or disclosed for other purposes. 
$051123 \mathrm{X}$

$9 / 15 / 2005$

Page 2 of 2

The PHI for which use has been determined to be necessary by the IRB includes:

1. Medical records of Implantable Cardioverter-Defibrillators (ICD) recipients who underwent follow-up examination at 3 month intervals from January 1, 2000 to May 31, 2005 at UCSD Medical Center.

This waiver was granted using expedited review procedures.

This study was reviewed by the IRB through expedited review procedure as authorized by 45 CFR 46.110 and 21 CRF 56.110 and falls under the following research category: (5) Research involving materials (data, documents, records, or specimens) that have been collected or will be collected solely for nonresearch purposes (such as medical treatment or diagnosis).

\author{
Mamie Gonzalez, Acting Director \\ Human Research Protections Program \\ Mailcode 0052 Phone: 858-455-5050 \\ E-mail: hrpp@ucsd.edu
}

Note: All Human Subject research conducted at the VA facility and/or utilizing VA/VMRF funds MUST BE APPROVED by the VA Research and Development Committee prior to commencing any research. In addition, please ensure that the clinical trial agreement or other funding is appropriately in place prior to conducting any research activities. IRB approval does not constitute funding approval.

Approval release date: $9 / 15 / 2005$ 